\title{
əThe Giant Nucleus Impactor (GNI)_A System for the Impaction and Automated Optical Sizing of Giant Aerosol Particles with Emphasis on Sea Salt. Part I: Basic Instrument and Algorithms
}

\author{
Jørgen B. Jensen, Stuart P. Beaton, Jeffrey L. Stith, and Karl Schwenz \\ Earth Observing Laboratory, National Center for Atmospheric Research, Boulder, Colorado \\ MARILÉ COLÓN-Robles ${ }^{\mathrm{a}}$ AND ROBERT M. RAUbeR \\ Department of the Atmospheric Sciences, University of Illinois at Urbana-Champaign, Urbana, Illinois \\ JOHN GRAS \\ Marine and Atmospheric Research, CSIRO, Aspendale, Victoria, Australia
}

(Manuscript received 25 June 2019, in final form 3 July 2020)

\begin{abstract}
Size distributions of giant aerosol particles (dry radius larger than $0.5 \mu \mathrm{m}$, sometimes referred to as coarsemode aerosol particles) are not well characterized in the atmosphere. Measurements are problematic for these particles because they (i) occur in low concentrations, (ii) have difficulty in passing through air inlets, (iii) may be dry or deliquesced particles, and (iv) if sampled by impaction, typically require labor-intensive methods. In this study, a simple, high-volume impaction system called the Giant Nucleus Impactor (GNI), based on free-stream exposure of polycarbonate slides from aircraft, is described along with an automated optical microscope-based system for analysis of the impacted particles. The impaction slides are analyzed in a humidity-controlled chamber (typically $90 \%$ relative humidity) that ensures deliquescence of soluble (typically sea salt) particles. A computer-controlled optical microscope with two digital cameras is used to acquire and analyze images of the aerosol particles. At relative humidities above deliquescence ( $74 \% \mathrm{RH}$ for sea salt), such particles will form near-spherical cap solution drops on the polycarbonate slides. The sea-salt mass in each giant aerosol particle is then calculated using simple geometry and published water activity measurements. The system has a sample volume of about $10 \mathrm{~L} \mathrm{~s}^{-1}$ at aircraft speeds of $105 \mathrm{~m} \mathrm{~s}^{-1}$. For salt particles, the measurement range is from about $0.7 \mu \mathrm{m}$ dry radius to at least $16 \mu \mathrm{m}$ dry radius, with a size-bin resolution of $0.2 \mu \mathrm{m}$ dry radius. The sizing accuracy was tested using polystyrene latex (PSL) beads of known size.
\end{abstract}

\section{Introduction}

Giant aerosol particles (e.g., Johnson 1976; dry radius $r_{d}>0.5 \mu \mathrm{m}$; sometimes also called coarse-mode aerosol) and ultragiant aerosol particles $\left(r_{d}>5 \mu \mathrm{m}\right)$ constitute an important part of the atmosphere's aerosol populations, in particular as they may contribute to a

¿ Denotes content that is immediately available upon publication as open access.

\footnotetext{
${ }^{\text {a }}$ Current affiliation: Science Systems and Applications, Inc., Hampton, Virginia.
}

Corresponding author: Jørgen B. Jensen, jbj@ucar.edu significant part of the total aerosol mass (Willeke and Whitby 1975). Giant aerosol particles have many sources, including marine (sea salt; Woodcock 1953; Lewis and Schwartz 2004; Andreae and Rosenfeld 2008; sulfate; Mouri et al. 1995), land surface (mineral dust; Johnson 1976; Hobbs et al. 1985; Weinzierl et al. 2017), biological (pollen, spores, and plant fragments; MatthiasMaser and Jaenicke 1994), industrial (e.g., pulp mill effluent; Hindman et al. 1977), and biomass burning (e.g., ash; Hobbs and Rangno 2004).

Giant and ultragiant aerosols, in particular sea salt, may play an important role in the formation of warm rain (e.g., Houghton 1938; Woodcock and Gifford 1949; Woodcock 1952; Johnson 1982; Tzivion et al. 1994; Cooper et al. 1997; Feingold et al. 1999; Szumowski et al. 1999; Lasher-Trapp et al. 2001; Rosenfeld et al. 2002; 
Blyth et al. 2003; Saleeby and Cotton 2004; Geresdi and Rasmussen 2005; Levin et al. 2005; Jensen and Lee 2008; Mechem and Kogan 2008; Knight et al. 2008; Arthur et al. 2010; Lowenstein et al. 2010; Rosenfeld et al. 2010; Freud and Rosenfeld 2012; Jung et al. 2015; Dagan et al. 2015; Jensen and Nugent 2017; Dadashazar et al. 2017) and their effects may be important for weather and climate prediction. The magnitude of the impact is controversial, with some studies suggesting only a small impact (e.g., Zhang et al. 2006; Knight et al. 2008; Lasher-Trapp et al. 2008; Hudson et al. 2009; Reiche and Lasher-Trapp 2010; Gerber and Frick 2012; Minor et al. 2011). Many of the above individual studies point to situations where the impact may be important, and to other situations where giant aerosol particles may not be important (e.g., Knight et al. 2008; Kogan et al. 2012; Dagan et al. 2015). Although first suggested more than 80 years ago (Houghton 1938), the effect of giant and ultragiant aerosol particles on warm rain formation has only recently been included in calculations of climate change (Posselt and Lohmann 2008).

Taken together, these prior studies indicate that it is extremely important to have accurate, high-sample-volume measurements of giant aerosol particles in order to be able to assess the impact of such aerosol particles on warm rain formation and for other reasons. Measurements of giant and ultragiant aerosol particles are rare as they are difficult and time consuming to sample, especially given that the concentration of these particles is typically very low, on the order of $0.1-1 \mathrm{~cm}^{-3}$ (marine air; Woodcock 1953); thus there is incomplete knowledge about their concentration, size, physiochemical composition, and spatial distribution.

Aerosol particles impacted on external glass slides (e.g., Woodcock and Gifford 1949) can be sized by optical microscopy, but this is usually a labor-intensive process which limits the amount of sampling and analysis. By doing the analysis at high relative humidity (Woodcock and Gifford 1949), it is possible to discriminate between hygroscopic particles and nonhygroscopic particles. Salt particles will form solutiondroplet spherical caps on the slide, and laboratory measurements of vapor pressure over salt solutions can be used to calculate the salt mass based on the volume of the spherical cap, the chamber humidity, and the assumed salt composition. For free-stream sampling from aircraft, impactors with an exposed sample area of $1 \mathrm{~cm}^{2}$ can typically sample $10 \mathrm{Ls}^{-1}$ depending on flight speed, and this provides large sample volumes for analysis. Short exposure times are particularly advantageous because it makes it possible to sample giant aerosol size distributions in cloud inflow air for individual clouds.
When sampling from an aircraft, internal filter and impactor samples can be used to analyze giant aerosol particles with high size resolution. In combination with electron microscopy techniques (e.g., Okada 1983; Mouri et al. 1995; Lasher-Trapp et al. 2008), samples may give detailed information on the size and chemical composition of individual particles. The main problem with airborne sampling using instrumentation in the cabin is that large particles cannot be decelerated sufficiently in air inlets to avoid particle impaction on the curved part of the inlet tubes. Such collisions may also lead to shattering of particles, thus distorting the size distribution. The severity of large particle loss varies among inlets; for example, Blomquist et al. (2001) quote a $50 \%$ passing efficiency for particles of $1.5 \mu \mathrm{m}$ radius for the National Center for Atmospheric Research community aerosol inlet. Other more advanced inlets, such as the Counterflow Virtual Impactor (CVI; Noone et al. 1988) and the Low Turbulence Inlet (LTI; Wilson et al. 2004; Huebert et al. 2004) have higher passing efficiencies for giant aerosol particles, but they both still suffer from particle loss for larger particles. Huebert et al. (2004) speculated that the passing efficiency changed as the walls of the tubing gradually became coated with salt aerosols in the course of many flight hours. The same study only examined particles with a maximum of $3.5 \mu \mathrm{m}$ aerodynamic radius; at $80 \%$ relative humidity this would correspond to a dry sea-salt radius of only about $1.6 \mu \mathrm{m}$.

Aerodynamic particle size spectrometers (e.g., TSI 3321) may be used to size giant aerosol particles using a laser velocimeter to determine the particle aerodynamic size. Such instruments may be able to size particles up to $9.1 \mu \mathrm{m}$ radius $(4.6 \mu \mathrm{m}$ dry radius, if sea-salt aerosol are measured at $80 \%$ relative humidity), but for airborne use these instruments are affected by the same air intake losses as explained above for other internal instruments. The aerodynamic particle sizers typically operate with a small sample volume of $17 \mathrm{~cm}^{3} \mathrm{~s}^{-1}$, i.e., about a factor 500 less than external impactors. One characteristic of aerodynamic particle sizers is that ambient particle sizes are measured, unless the air is preheated (using heaters or dynamic heating due to deceleration) prior to entering the instrument. For an aircraft flying at $105 \mathrm{~m} \mathrm{~s}^{-1}$, the dynamic heating is roughly $5 \mathrm{~K}$, which may lead to a $30 \%$ reduction in relative humidity, and this may significantly impact the measured aerosol size. For many applications it is necessary to calculate the dry mass of an aerosol particle, thus it is important to know if the aerosol particle at the time of measurement is at ambient size, dry size, or some intermediate size.

External optical scattering probes [e.g., PMS forward scattering spectrometer probe (FSSP) and DMT cloud 
droplet probe (CDP)] can size giant aerosol particles automatically (e.g., Lasher-Trapp and Stachnik 2007; Lowenstein et al. 2010). As they measure an optical radius, which is defined as the radius of a particle with a specified index of refraction that scatters a given amount of light, such instruments cannot distinguish sea-salt particles from more dilute cloud drops composed of other substances. Due to the Mie curve for pure water drops being multivalued (a given amount of scattered light may have resulted from drops of several different sizes), such probes have considerable sizing uncertainty (see, e.g., Pinnick et al. 1981; Cox et al. 2019). Scattering probes, such as the FSSP, have typical sample volumes of about $20 \mathrm{~cm}^{3} \mathrm{~s}^{-1}$ or less, and so require about $12 \mathrm{~h}$ of flight to sample $1 \mathrm{~m}^{3}$ of air. Cabin-mounted aerosol spectrometers (e.g., TSI 3340; Murphy et al. 2019) will also be limited by inlet losses for larger particles.

Imaging probes (e.g., PMS 260-X optical array probe, $10 \mu \mathrm{m}$ resolution) or digital cameras (e.g., SPEC CPI, $2.3 \mu \mathrm{m}$ resolution) may also be used to determine giant aerosol concentrations and size distributions (e.g., Lasher-Trapp and Stachnik 2007), and for the higher-resolution probes like the CPI, it may be possible to make rough estimates of solubility through examination of the particle shape.

Although laser probes have the advantage of automation, external impactors in free-stream provides much larger sample volumes $\left(\approx 10 \mathrm{~L} \mathrm{~s}^{-1}\right.$, or about a factor 500 higher than an FSSP probe), high size resolution, large size range, and the ability to discriminate among hygroscopic and nonhygroscopic material. External impactors also have several disadvantages due to impact splashing and breakup, and due to coalescence between particles on the slide. These potential problems will be examined in a companion paper (J. B. Jensen et al. 2020, unpublished manuscript hereafter referred to as Part II).

In the following we describe the construction and operation of the Giant Nucleus Impactor (GNI), an automatic system for analysis of giant and ultragiant nuclei captured on external impaction slides. Section 2 describes the manual impaction system, and in section 3 we document the hardware used for the automatic humidity-controlled optical microscope system. The software algorithms used to determine particle sizes and shapes are presented in section 4 , and the equations for determining the soluble particle mass are given in section 5 . The calculation of sample volume is described in section 6 . Handling of the slides may lead to contamination, which can lead to false counts; the investigation of blank "control slides" is presented in section 7. In section 8 we

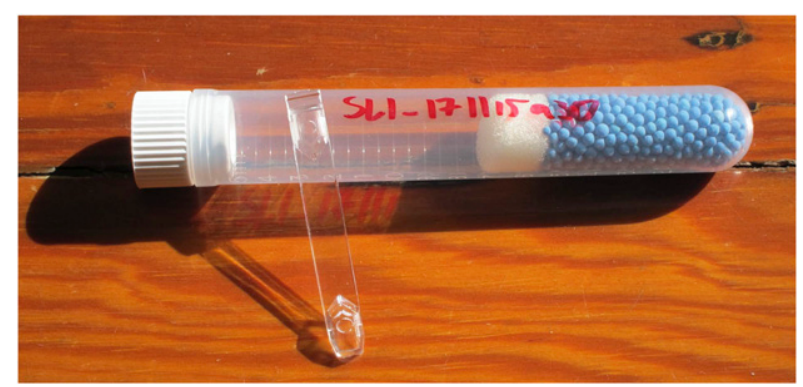

FIG. 1. Photo of a molded polycarbonate slide. The flat surface is $23 \mathrm{~mm}$ long $\times 6.37 \mathrm{~mm}$ wide, and it is mounted perpendicular to the airflow during exposure. The photo also shows a storage test tube, including blue desiccant and a foam plug.

show some results from a field experiment, and section 9 contains a summary.

\section{Slides and impactor}

The impaction slides are injection-molded polycarbonate slides with a width of $6.37 \mathrm{~mm}$ (Fig. 1). The effective area used for analysis is $4.4 \mathrm{~mm}$ wide and $20.7 \mathrm{~mm}$ long. The reduction in analyzed width is done to avoid the slide edge regions that (due to the manufacturing process) may be slightly curved, thus making focus difficult or impossible in the microscope. The slides are springloaded onto a $6.35 \mathrm{~mm}$ stainless steel rod before exposure (Fig. 2). The steel rod is cut to provide a flat 6-mm-wide surface behind the slide, i.e., slightly narrower than the polycarbonate slide.

The slides were uncoated as water has a very high contact angle, typically $82^{\circ}$, on polycarbonate (Accu Dyne Test 2019). The slides are stored individually in capped test tubes prior to and after exposure from the aircraft; the sample tubes are desiccated individually with an open-cell foam plug between slides and desiccant (Fig. 1).

The polycarbonate slides are exposed to the airstream using a system that is operated manually from inside the aircraft. An airfoil shaped strut of length $500 \mathrm{~mm}$ is used to hold the steel rod and microscope slide in place during the exposure (Fig. 2). Inside the aircraft, a double airlock system is used to enable slides to be exposed from a pressurized cabin. The slide rod is extended through the airlocks, through the $500 \mathrm{~mm}$ strut and a further $100 \mathrm{~mm}$ from the airfoil strut, thus exposing slides $600 \mathrm{~mm}$ from the skin of the aircraft. A brass sleeve covers the slide until the last $30 \mathrm{~mm}$ of the extension. Thus, apart from the time taken to mount and unmount the slide on the steel rod, the slide is only uncovered during the actual external exposure. The exposure time (typically $5-15 \mathrm{~s}$ near sea surface) is recorded with a triggered electric 


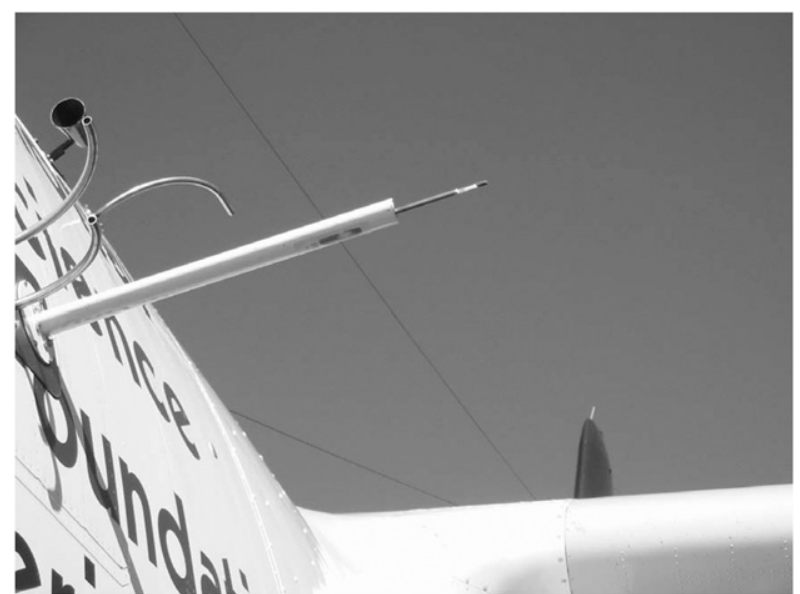

FIG. 2. The impaction strut, mounted on the NSF/NCAR C-130 research aircraft, with a slide fully exposed.

contact during slide exposure. In an attempt to have the slide facing perpendicularly to the approaching airflow, the slide is angled down by about $2^{\circ}$ during exposure in order to counteract the typical $\mathrm{C}-130$ pitch angle $\left(1.5^{\circ}-2.5^{\circ}\right.$, aircraft nose up) during low altitude flying. The width of the slide is important for the collision efficiency of aerosol particles with the slide (see section 6), whereas the potentially important effects of drop shattering in high-speed impact is detailed in Part II.

\section{The microscope system}

The GNI microscope system is an optical microscope with two digital cameras, a large motorized $x-y$ stage, a $z$ motor drive for focusing the vertical camera, and a system for providing humidified air (Fig. 3). The entire system is designed to run using computer control with minimal operator input after startup. The microscope can handle 40 polycarbonate slides in a batch. The image acquisition for each slide takes about $3 \mathrm{~h}$, the subsequent analysis of the image data to determine aerosol sizes takes another $3 \mathrm{~h}$ per slide, and it takes about $2 \mathrm{~h}$ for loading and unloading slides, and for configuring the acquisition program and analysis program for a batch of 40 slides.

\section{a. Microscope and camera}

The exposed polycarbonate slides are inserted into small cassettes, each capable of holding four slides. Five cassettes are then inserted into a small sealed glass chamber, and two of these glass chambers can be mounted next to one another in the microscope system; see Fig. 3. Thus, the system has the capacity to analyze 40 slides in a batch by moving the slides in two dimensions relative to the microscope.
The GNI microscope (Table 1) is a custom microscope with dual columns; the primary optical column is vertical, looking perpendicular onto the slides in order to image the perimeter of particles on the glass slides. The other optical column is mounted to give a nearhorizontal view of the particles; this camera views slightly downward at an angle of $3^{\circ}$ to the slide surface. It is only used in a manual mode to obtain the aspect ratio of the deliquesced particles (section 5). The objectives are designed to image through glass up to $1.1 \mathrm{~mm}$ thick; this allows for viewing slides through the top and sidewalls of the slide glass chamber. Each microscope column is fitted with a monochrome digital camera with $1600 \times 1200$ pixel resolution. For a $20 \times$ objective and with $7.4 \mu \mathrm{m}$ square camera pixels, the effective pixel size on the slide is $0.37 \mu \mathrm{m}$ with a field of view of $592 \mu \mathrm{m} \times 444 \mu \mathrm{m}$ for each image. A slide contains a total of $10 \times 35$ independent camera views (images) to cover a total area of $0.92 \mathrm{~cm}^{2}$. The cameras are operated in 8-bit depth digitization mode. A shutter is mounted in front of the vertical column camera; this is used to acquire dark images for illumination equalization (section 4b). Each microscope has a separate light source using fiber-optic-coupled halogen light sources to give broadband white light.

\section{b. Scanning stage}

A large horizontal $x-y$ stage is used to scan over a slide and move between the 40 slides in the two chambers. A $z$ drive moves the vertical column and camera up and down in order to obtain the optimum focus. Image acquisition, stage control including focus, and temperature control are all accomplished using an NCAR-developed program with standard hardware (Table 1).

\section{c. Temperature control}

The entire microscope system and air humidifying system (using a supersaturated $\mathrm{KNO}_{3}$ salt bubbler) is placed in an insulated temperature-controlled enclosure which is maintained at $33.7^{\circ} \mathrm{C}$. Temperature is measured with an accuracy of $\pm 0.34^{\circ} \mathrm{C}$ in the large enclosure of the microscope, above the salt bubbler, and at the exit of the slide chamber. Temperature stability of the enclosure air is about $0.1^{\circ} \mathrm{C}$, while that of the salt and chamber is about $0.02^{\circ} \mathrm{C}$ over a 36 -h period.

\section{d. Air humidifier}

The humidity system (Fig. 3) ensures that sea-salt particles deliquesce and form spherical cap solution drops while the slides are in the glass chambers. The humidity system has a nearly closed loop of continuously circulating air that passes from an air pump, bubbling 


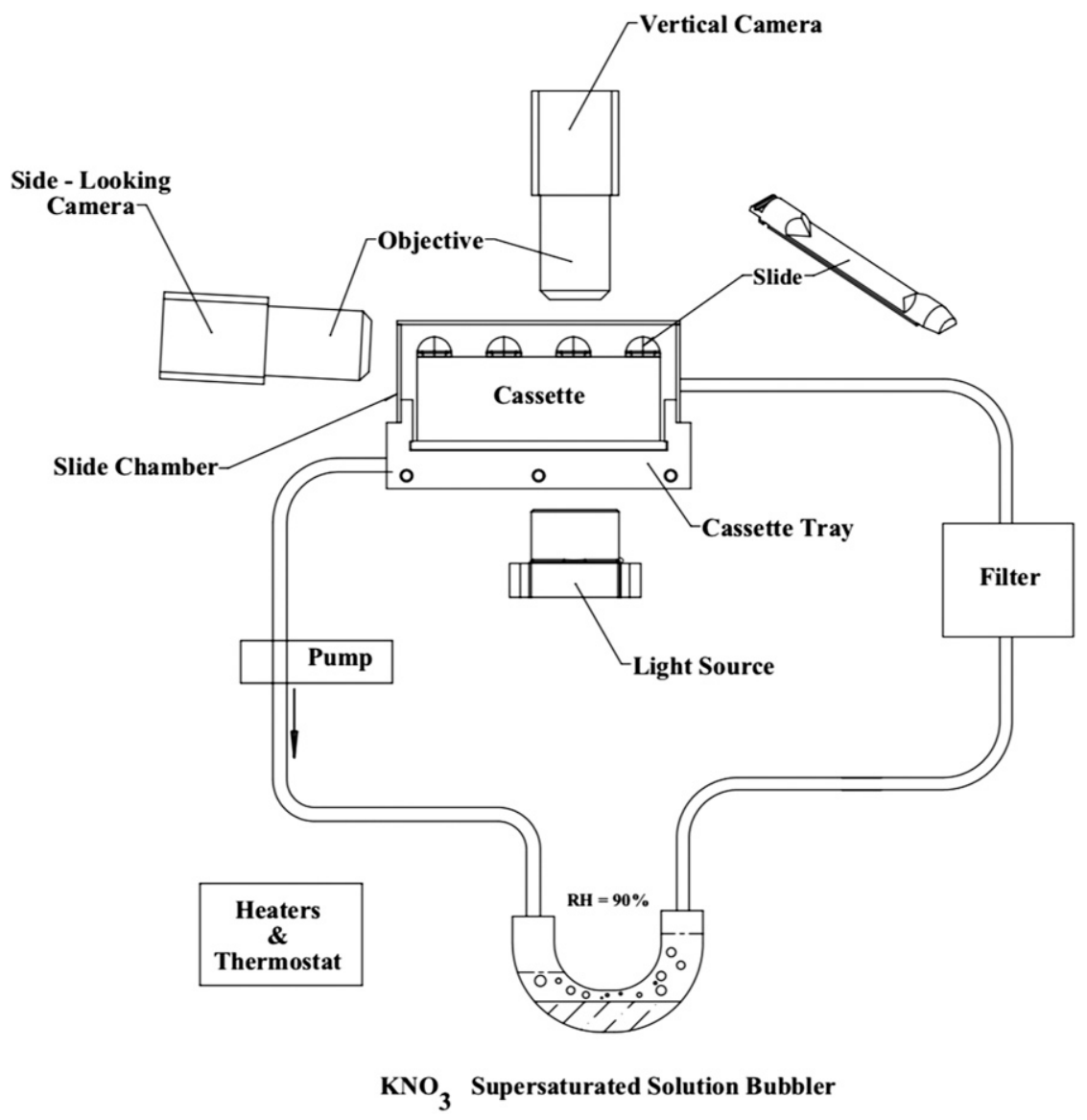

FIG. 3. Schematic of the GNI optical microscope system. Two glass slide chambers (only one shown), each with 20 polycarbonate slides, are installed in the center of a two-axis motorized stage. The main microscope and camera system views vertically from the top. A second view of some of the aerosol particles can be obtained using the horizontal microscope seen in the upper left; this microscope is used to obtain shape information for selected aerosol particles. The saturated salt bubbler, part of the humidity control system, can be seen in the bottom part of the figure. Air circulates from the salt bubbler, through a filter, and into the slide chambers. From there the air is returned through the pump and to the salt bubbler. The entire GNI microscope system is inside a $0.6 \mathrm{~m}^{3}$ chamber that is temperature controlled at $33.7^{\circ} \mathrm{C}$.

through a glass u tube with a saturated salt solution, through a particulate filter, through the glass chambers with the slides, and then back to the pump. The aim is to provide a relative humidity of about $90 \%$ by passing the air over a saturated $\mathrm{KNO}_{3}$ solution.

After loading the slides into the microscope glass chambers, and after inserting the chambers into the microscope cabinet, the microscope cabinet is allowed to heat to a stable temperature of about $33.7^{\circ} \mathrm{C}$. Acquisition of microscope images typically starts more than $12 \mathrm{~h}$ later in order to have instrument at thermodynamic equilibrium. The 12-h period also allows for the aerosol particles to attain their equilibrium size. The temperature inside the microscope cabinet $\left(T_{c}\right)$ is logged every time a microscope image is acquired. This temperature is used to calculate two vapor pressures: (i) Eq. (4) in
Apelblat and Korin (1998) is used to calculate $e_{\mathrm{KNO}_{3}}\left(T_{c}\right)$, i.e., the water vapor pressure over a supersaturated $\mathrm{KNO}_{3}$ solution as a function of temperature. (ii) Based on the same microscope cabinet temperature, the saturated water vapor pressure $e_{s}\left(T_{c}\right)$ is calculated using Bolton's (1980) Eq. (10). These two vapor pressures are then used to calculate the saturation ratio $S=e_{\mathrm{KNO}_{3}}\left(T_{c}\right) / e_{s}\left(T_{c}\right)$ of the air in the slide chambers, with one such calculation per slide image. As a check, the relative humidity is also measured with a lower accuracy Honeywell sensor after the air leaves the slide chambers (Table 1).

The elemental composition of selected particles on selected slides were determined using energy-dispersive $\mathrm{X}$-ray analysis (EDXA). This was done to investigate if part of the $\mathrm{KNO}_{3}$ solution in the bubbler could be carried to the slides in the microscope chamber, although 
TABLE 1. GNI microscope system components.

\begin{tabular}{|c|c|c|}
\hline Component & Manufacturer & Part or characteristic \\
\hline Microscope manufacturer & Leeds Precision & Custom \\
\hline Objectives & Olympus & LCPlan-apo 20x \\
\hline Cameras & Optronics & MicroFire Monochrome \\
\hline Pixel resolution (camera) & & $1600 \times 1200$ \\
\hline Effective pixel size on slide & & $0.37 \mu \mathrm{m}$ \\
\hline Single-image field of view & & $592 \mu \mathrm{m} \times 444 \mu \mathrm{m}$ \\
\hline Number of images per slide & & $10 \times 35=350$ (typically) \\
\hline Analyzed area per slide & & $0.92 \mathrm{~cm}^{-2}$ \\
\hline Image depth & & 8-bit monochrome \\
\hline Light sources & Schott & ACE-1 fiber-optic halogen \\
\hline Vertical column shutter & Uniblitz & VS 25 \\
\hline Vertical column diffuser & Leeds Precision & Custom \\
\hline Horizontal column diffuser & Schott & Fostec 2 in. $\times 2$ in. AO8903 \\
\hline Horizontal scanning stage & Ludl Elec. Prod., Ltd. & $20 \mathrm{~cm} \times 10 \mathrm{~cm}$ \\
\hline Vertical camera movement & Ludl Elec. Prod., Ltd. & $\mathrm{Z}$ drive \\
\hline Instrument hardware control & Linux PC & \\
\hline Multifunction IO card & LabJack T7 & \\
\hline Camera interface & Adaptec & IEEE-1394 \\
\hline Instrument software control & NCAR/RAF & Custom \\
\hline Microscope cabinet temperature setting & & $33.7^{\circ} \mathrm{C}$ \\
\hline Temperature sensors & Wavelength Electronics & TCS610 \\
\hline Temperature sensor uncertainty & & $0.34^{\circ} \mathrm{C}$ \\
\hline Air temperature stability & & $0.1^{\circ} \mathrm{C}$ \\
\hline Salt bubbler temperature stability & & $0.02^{\circ} \mathrm{C}$ \\
\hline Relative humidity sensor & Honeywell HIH3610 & $2 \%$ \\
\hline Air filters & Balston & DFU \\
\hline Supersaturated salt solution & Acros Organics & $\mathrm{KNO}_{3}$ and deionized water \\
\hline PSL calibration beads & Thermo Scientific & $2.000,3.9895,7.485,14.94,24.65$, and $34.65 \mu \mathrm{m}$ mean radius \\
\hline
\end{tabular}

an inline filter was meant to prevent this. In a laboratory at the University of Colorado Department of Geology, a microprobe was used to examine the aerosol material on the slides. The vast majority of material was $\mathrm{Na}, \mathrm{Cl}$, and several minor components from sea salt; very little nitrogen was found, thus suggesting the hygroscopic properties of the aerosols (even after about 5 days in the humidified microscope) was consistent with largely unmodified sea salt.

There are several reason for selecting a relative humidity of about $90 \%$. Sea-salt particles form spherical solution drops at relative humidity above about $74 \%$ (spherical caps on the microscope slide). Thus, when viewed from above, they form a nearly circular pattern on the microscope images. This will contrast with particles consisting, for example, of mineral dust, pollen, or other biological material, which will largely retain their dry sizes at this relative humidity. Mineral dust, even with small amounts of soluble coatings (e.g., sulfates) on the surface, is unlikely to show the circular pattern on the images, and the particle perimeter can thus be used to differentiate between salt and other particles. The $90 \%$ relative humidity is also advantageous as the sea-salt particles will have grown somewhat from their dry size (the spherical cap base radius on the images is typically 3 times the aerosol dry spherical radius), and this will make identification and sizing more accurate. Increasing the relative humidity much higher to near 100\% [Woodcock and Gifford (1949) used 99\%] will make sea-salt particles grow much more; this is more likely to lead to coalescence among solution drops on the slides, which is to be avoided, and sizing actually becomes more uncertain as the equilibrium solution drop radius increases rapidly with even a small change in relative humidity.

\section{e. Focus}

The microscope has a $1 \mu \mathrm{m}$ depth of field, thus the microscope surface must be very flat and the slide must be mounted perpendicular to the primary vertical microscope optical axis. Accordingly, an autofocus algorithm was implemented which lowers the vertical microscope and then records images while the column is stepped upward in small increments. At each vertical $0.3 \mu \mathrm{m}$ step, an image is recorded and a focus quality parameter $s$ is calculated as

$$
s=\frac{\left[\sum_{x=1}^{N_{x}} \sum_{y=1}^{N_{y}-1}\left(P_{x, y+1}-P_{x, y}\right)^{4}\right]^{1 / 4}}{\overline{P_{x, y}}},
$$


TABLE 2a. Symbol list.

\begin{tabular}{ll}
\hline \hline Symbol & \\
\hline$a_{w}$ & Water activity \\
$b$ & Radius of aircraft fuselage \\
$c$ & Polynomial coefficients \\
$d$ & Slide distance off the skin of the aircraft \\
$e$ & Vapor pressure \\
$h$ & Spherical cap height \\
$i$ & Size bin index (width of $0.2 \mu$ m dry radius) \\
$m_{\text {drop }}$ & Mass of solution drop \\
$m_{s}$ & Mass of sea salt in particle \\
$n_{x}, n_{y}$ & Maximum number of shaded particles in the $x$ and $y$ \\
& $\quad$ directions, respectively \\
$r_{\alpha}$ & Radial distance \\
$r_{a}$ & Radius of ambient salt solution drop \\
$r_{b}$ & Radius of spherical image (spherical cap drop base) \\
$r_{c}$ & Radius of sphere with same volume as spherical cap \\
$r_{\mathrm{be}}$ & Mean radius of PSL beads (manufacturer's data) \\
$r_{d}$ & Radius of dry spherical salt particle \\
$r_{f}$ & Radius of sphere for which the spherical cap drop \\
& forms part \\
$r_{m}$ & GNI determined modal bead radius \\
$s$ & Focus quality parameter \\
$t$ & Slide exposure time \\
$x, y$ & Pixel index in the $x$ and $y$ directions, respectively \\
\hline
\end{tabular}

where $N_{x}=1600$ and $N_{y}=1200$ are the numbers of pixels along and across the camera CCD, and $P_{x, y}$ is the light intensity for pixel $(x, y)$; complete symbol lists are given in Tables $2 \mathrm{a}-\mathrm{c}$. Note that the sum was only carried out for those pixel pairs that have $P_{x, y+1}>\overline{P_{x, y}}$. The image in the vertical sequence that produced the maximum value of $s$ has the highest contrast, and only this image is saved and used for analysis.

\section{Analysis of images}

\section{a. Sample images}

The microscope acquired data are published in Jensen and Beaton (2019). An example of a single slide image is shown in Fig. 4. The slide was sampled during the 2008 VAMOS Ocean-Cloud-Atmosphere-Land Study (VOCALS) project off the coast of Chile; for an overview of VOCALS, see Wood et al. (2011). The image shows a large number of mostly circular particles (spherical cap solution drops of sea salt), and a few particles that are not quite round. There may be surface effects that cause minor deviations from circular images. Digitally overlaid on the image is a grid with a separation distance of 100 pixels $(37 \mu \mathrm{m})$.

The image also shows several other noteworthy features. Inside the largest particle is some material that is not dissolved. At $90 \%$ relative humidity this is unlikely to be salt, but it is possibly organic matter or marine
TABLE 2b. Symbol list, continued.

\begin{tabular}{ll}
\hline \hline Symbol & \\
\hline$A$ & Aspect ratio of spherical cap \\
$C_{i}$ & $\begin{array}{l}\text { Count size distribution of particles that impacted on } \\
\text { slide and can be sized (i.e., not on edges of images) }\end{array}$ \\
$F_{\text {enh }}$ & Concentration enhancement factor \\
$E$ & Impaction efficiency \\
$H$ & Height of an image (y direction) \\
$I_{x, y}$ & Pixel values after scaling \\
$I_{m}$ & Median value of pixel values after scaling \\
$L$ & Length of an image ( $x$ direction) \\
$M_{s}, M_{w}$ & Molar weights of sea salt and water, respectively \\
$N$ & Number of microscope images \\
$N_{x}, N_{y}$ & Number pixels in the $x$ and $y$ directions, respectively \\
$N_{\mathrm{St}}$ & Modified drop Stokes number \\
$P_{x, y}$ & Raw pixel value \\
$R_{v}$ & Gas constant for water vapor \\
$\mathrm{RH}$ & Chamber relative humidity (typically $90 \%)$ \\
$S_{a}$ & Ambient saturation ratio during slide exposure \\
$S_{c}$ & Microscope slide chamber saturation ratio during \\
& imaging \\
$S_{x, y}$ & Spline fit to raw pixel values \\
$\bar{S}$ & Average of spline fit to raw pixel values for an image \\
$T_{a}$ & Ambient temperature during slide exposure \\
$T_{c}$ & Chamber temperature \\
$T_{v}$ & Vaisala sensor temperature \\
$U$ & Airspeed \\
$V$ & Sample volume during slide exposure \\
$V_{\text {cap }}$ & Volume of spherical cap \\
\hline &
\end{tabular}

insoluble carbonaceous material. Based on examination of thousands of images, such undissolved material, if present, constitute only a very small fraction of the solution drop volume. There is also evidence of an impact spreading circle around the largest particle; this will be discussed in Part II.

In the left part of a second example image (Fig. 5) there are two lightly shaded circular particles (see arrows); these may be particles with a high degree of organic surfactant coating (Finlayson-Pitts and Pitts 2005) that reduces the surface tension. The lower surface tension results in a flatter spherical cap solution drop, and thus a lighter shade of gray when viewed from above in the microscope. Typically, such particles occur only in a few percent of the total number of particles.

The following sections will describe in detail how images are analyzed and salt particle sizes are determined.

\section{b. Illumination equalization}

The digital cameras have very low noise and dark current values when not illuminated. Thus, it was not necessary to remove the dark pixel values from the signal in an image. However, the slide illumination intensity is not completely uniform due to the geometry of the cassettes holding the slides. Thus, the pixel values were fitted with a two-dimensional spline (function csa2d of the 
TABLE 2c. Symbol list, continued.

\begin{tabular}{ll}
\hline \hline Symbol & \multicolumn{1}{c}{ Meaning } \\
\hline$\alpha$ & Angle from center of gravity \\
$\beta_{i}$ & Fractional reduction in sample area due to edge \\
& requirement \\
$\eta$ & Dynamic viscosity of air \\
$\nu$ & Number of ions that a salt molecule can dissociate \\
& into \\
$\rho_{s}, \rho_{\mathrm{so}}, \rho_{w}$ & Density of sea salt, solute, and water, respectively \\
$\sigma$ & Surface tension of water against air \\
$\sigma_{r_{\alpha}}$ & Standard deviation of radial distance for a particle \\
$\chi$ & Mass fraction of sea salt in a solution \\
$\Phi$ & Practical osmotic coefficient \\
\hline
\end{tabular}

ngmaths library; NCAR/CISL 2019). The corrected pixel light intensity $I_{x, y}$ was found from the raw pixel light intensity and the spline using

$$
I_{x, y}=P_{x, y}-\left(S_{x, y}-\bar{S}\right)
$$

where $P_{x, y}$ is the raw pixel intensity value for pixel $(x, y)$, $S_{x, y}$ is the spline fit of $P_{x, y}$, and $\bar{S}$ is the average value of the spline fit for the image. The above equation removes most of the gradual light illumination change across an image, while preserving the signals of the particles to a very high degree.

Next the median light level $I_{m}$ is found by ranking all $1200 \times 1600$ values of $I_{x, y}$ for an image. The determination of a particle perimeter is based on shading to a threshold level, here chosen as $85 \%$ of $I_{m}$. Thus, a pixel is considered shaded if its light intensity $I_{x, y}$ is below the following threshold value:

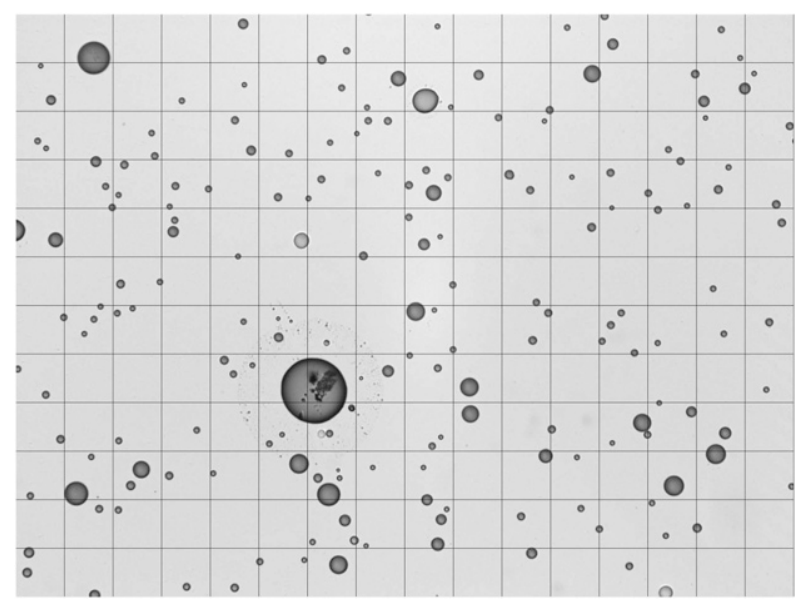

FIG. 4. Image 133 of 350 images from slide 3 exposed from the C-130 in the marine boundary layer as part of the VOCALS project. A grid for each 100 pixels has been overlaid on the image, thus the grid separation is $37 \mu \mathrm{m}$. This particular slide was exposed on 1346:37.2-1347:03.5 UTC 18 Oct 2008 at an altitude of $150 \mathrm{~m}$. The largest particle contains some undissolved material.

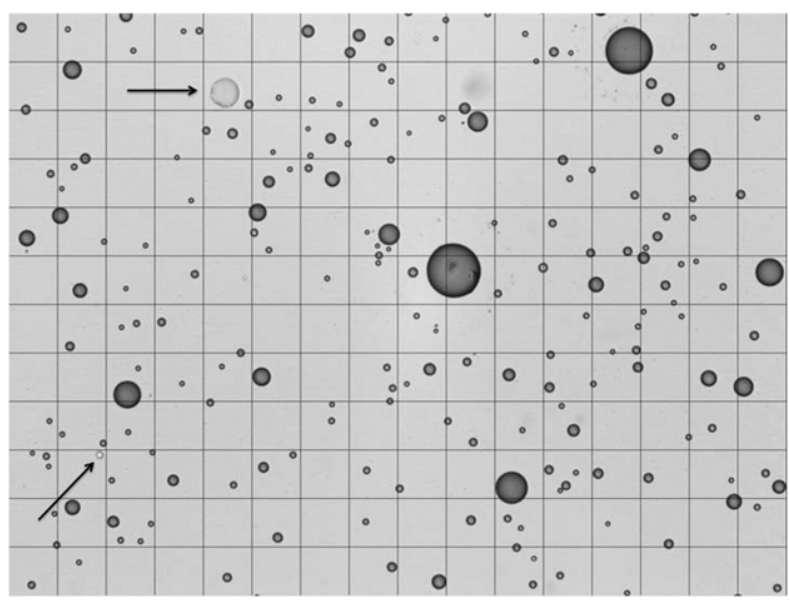

FIG. 5. Image 51 from the same slide as shown in Fig. 4. The vast majority of particles show a near-uniform edge contrast and shading. Two particles are much lighter; see arrows in the left part of the image. We hypothesize that these are much "flatter" spherical cap drops, with the reduction in height likely being caused by unusually strong organic coatings. Such organic coatings reduce the surface tension of the drops.

$$
I_{x, y}<0.85 I_{m} .
$$

\section{c. Optical detection and habit classification}

Particles on the stored images are detected using the above threshold approach. The images are scanned line by line, using Eq. (3) for determining shaded particles. Once a shaded pixel is found, a recursive eight-way connected-component algorithm is used to determine the shaded particles that touch one another, either on the sides of pixels or through corners of pixels. When all shaded pixels have been found for a given particle (i.e., all connected shaded pixels), a different algorithm is used to determine the particle perimeter. This recursive algorithm uses 4 directions, by requiring that an unshaded, external pixel must exist either above, to the right, below, or to the left of a pixel to identify it as a perimeter pixel. For the image shown in Fig. 4, the corresponding particle perimeters are shown in Fig. 6 (all particles, regardless of shape).

An example of the steps used in processing of the images is followed for the largest particle shown near the center of Fig. 6. The perimeter set of pixels for this round particle is shown in Fig. 7. The large $\times$ symbol shows the "center of gravity," calculated on the basis of the perimeter pixels. To characterize the perimeter, a sequence of 64 regularly spaced radial lines emanating from the center of gravity were calculated. The intersection of each of these 64 lines with lines connecting the perimeter points was subsequently determined, and the distance $\left(r_{\alpha}\right)$ from the center of gravity to the perimeter for each of the 64 lines was found. 


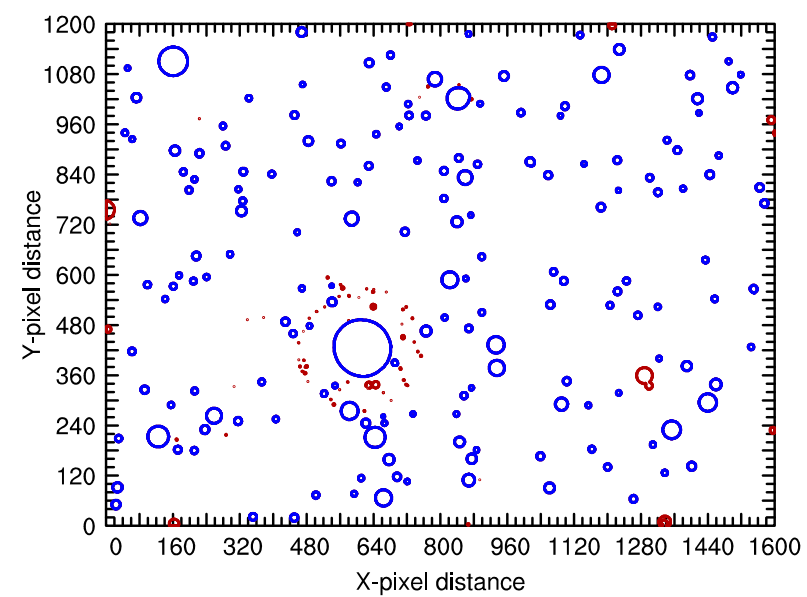

FIG. 6. Particle perimeters calculated based on the image shown in Fig. 4. Blue color: Perimeter pixels of all round particles, which do not touch the image edge and which are identified as large sea-salt particles (for algorithms, see text). Red color: Perimeter pixels of (i) all irregular particles, (ii) all particles that touch the image edge, and (iii) round particles that are too small (for criteria, see section 6). Red particles are discarded from further analysis. Notice that many of the smallest particles can been seen in a circular area around the largest particle. Such impact-spreading circles will be further discussed in Part II.

A simple requirement is then used for determining if a particle is "round." If the standard deviation $\left(\sigma_{r_{\alpha}}\right)$ of the 64 values of $r_{\alpha}$ has $\sigma_{r_{\alpha}} / \bar{r}_{\alpha}<0.15$, then a particle is considered round. For slides exposed in the marine boundary layer, such round particle images are classified as sea-salt particles. For slides exposed in other environments, it is possible that round images may

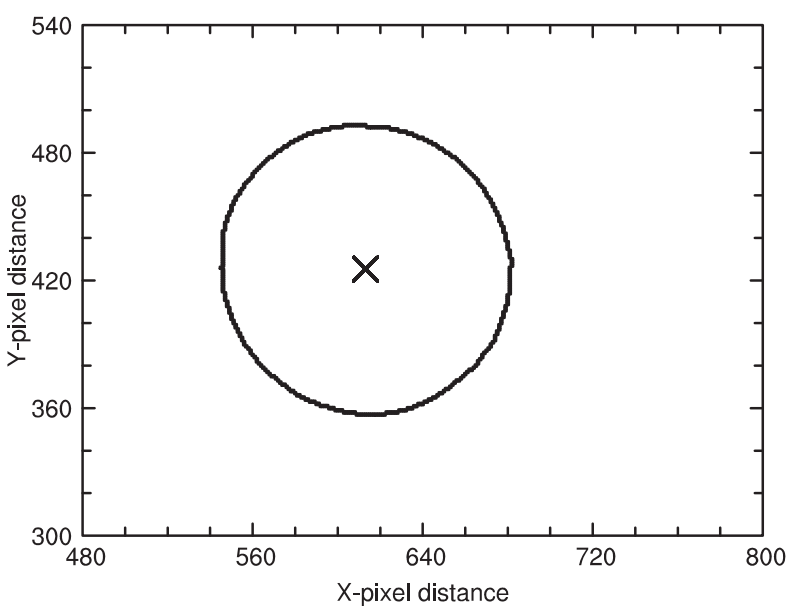

FIG. 7. Particle perimeter points as found by the shading threshold algorithms. The large $\times$ symbol is the center of gravity of the perimeter points. The analysis is done for the largest particle shown in Fig. 6.

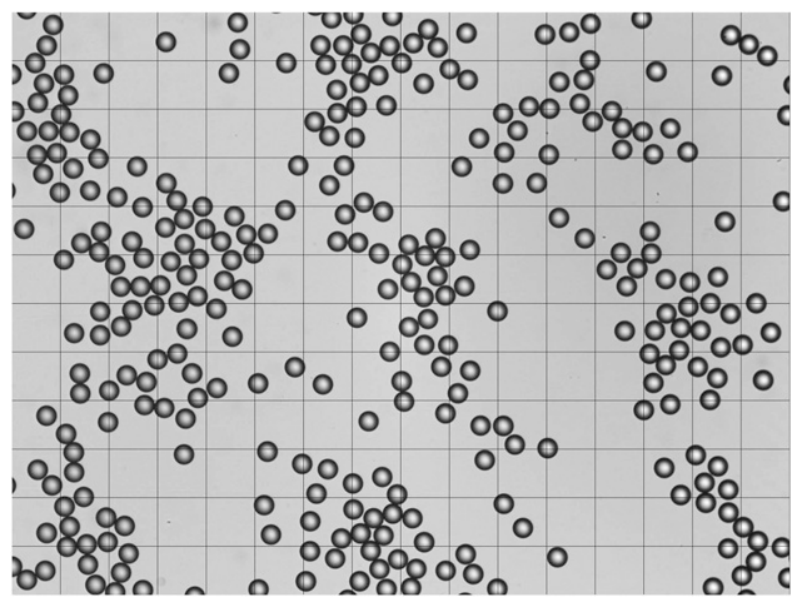

FIG. 8. Image of 7.5- $\mu$ m-radius calibration polystyrene latex (PSL) beads on a GNI slide. Focus was done manually on the bead perimeter, due to the different internal image intensity of the spherical PSL beads (very bright, this figure) as opposed to the somewhat darker centers of the spherical caps, see Fig. 4. Only nontouching beads were included in the image analysis.

results from different compositions (e.g., sulfates). The perimeters of all round particles (of sufficient size and not touching the image edge) are shown with blue in Fig. 6. The same figure shows with red the particles that are not round, are too small (dry radius $r_{d}<0.7 \mu \mathrm{m}$ ), or that are touching the image edge.

As any particle that touches the edge of an image is not analyzed, this makes the sample area within an image dependent on particle size. This will be further discussed in section 6 . The size of an individual particle is thus determined by averaging over 64 directions; to simplify the notation in the following sections, we will refer to the image determined radius of a particle as $r_{m}=\bar{r}_{\alpha}$.

\section{d. Sizing of calibration beads}

Six slides were prepared with polystyrene latex (PSL) beads of known sizes (nominally 2, 4, 7.5, 15, 25, and $35 \mu \mathrm{m}$; see also Table 3 ). These were then imaged in the GNI microscope in order to compare the microscope calculated mean bead size $\bar{r}_{m}$ with that specified by the manufacturer of the PSL beads $\left[\bar{r}_{\mathrm{be}}\right.$; Duke Scientific/Thermo Fisher; National Institute of Standards and Technology (NIST) traceable size determination], thus providing a calibration of the sizing system and algorithms. A sample image of a slide with PSL beads with mean radius $7.485 \mu \mathrm{m}$ (manufacturer's value) is shown in Fig. 8; notice the apparent uniformity in bead sizes. Due to nebulizing problems with particles of $r_{\text {be }}$ of $4 \mu \mathrm{m}$ and larger, the bead solution fluid for these sizes was dripped onto the slide and the beads were 


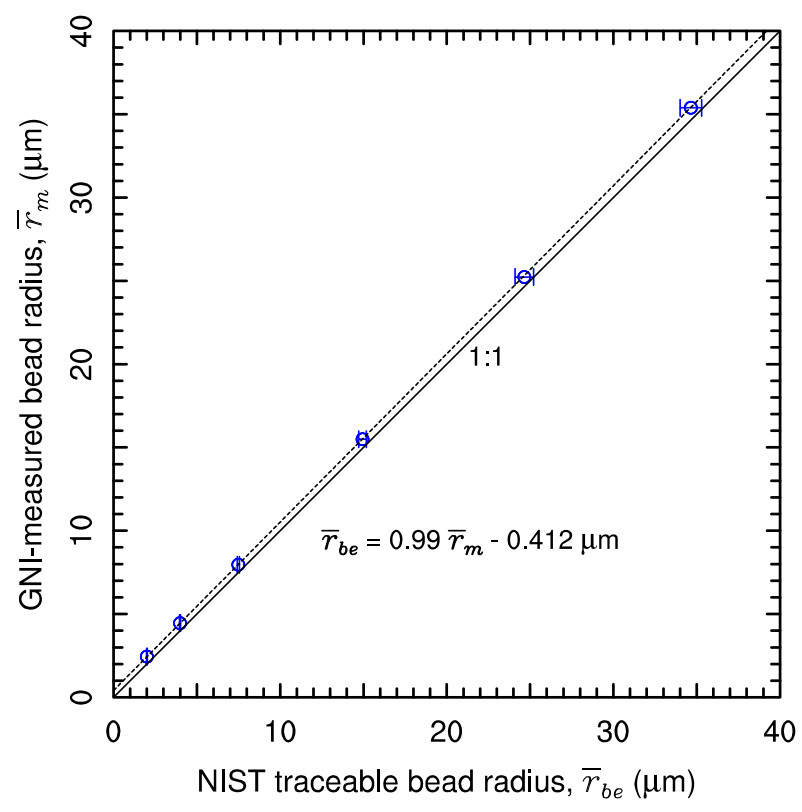

FIG. 9. GNI measured mean bead radius $\left(\bar{r}_{m}\right)$ for six bead sizes (see example in Fig. 8) as a function of the manufacturer's mean bead radius $\left(\bar{r}_{\text {be }}\right)$. The GNI measure bead radius $\left(\bar{r}_{m}\right)$ was determined by averaging over all sized particles with $r_{m}$ within $\pm 20 \%$ of the manufacturer's mean bead radius. Touching beads are excluded from analysis. The uncertainty of the manufacturers mean bead radius is shown with the horizontal distance between the vertical bars. The solid line shows the 1:1 fit between $\bar{r}_{\text {be }}$ and $\bar{r}_{m}$. The dashed line shows a fit, as given by the equation in the figure; this fit has an average error of less than $0.2 \%$ of the $\bar{r}_{m}$ values.

viewed through the center of the still liquid drop on the slide. For the $r_{\mathrm{be}}=2 \mu \mathrm{m}$ size, the normal nebulizer method was used, and the slide was viewed while dry. A comparison with dry slides with glass calibration beads showed near similar results (not shown). For the PSL beads, the mean size of the observed distribution, $\bar{r}_{m}$, is compared to that specified by the bead manufacturer, $\bar{r}_{\text {be }}$, see Fig. 9. A regression analysis with $\bar{r}_{\text {be }}$ as the independent variable resulted in a linear fit of $\bar{r}_{m}=1.0101 \bar{r}_{\text {be }}+0.4158 \mu \mathrm{m}$, with mean and maximum errors of less than $0.2 \%$ and $0.35 \%$, respectively. Figure 9 also shows a correction expression that fits the data with mean and maximum errors of $0.2 \%$ and $0.35 \%$, respectively. This expression is used to find the best estimate of the radius of the base of the spherical cap, $r_{b}$ (units of $\mu \mathrm{m}$ ):

$$
\bar{r}_{b}=0.990 \bar{r}_{\alpha}-0.412 \text {. }
$$

Thus, the optical microscope sizing results in a small overestimate of the particle base radius size, for which Eq. (4) is used for correction. The value of the correction is only about 1-2 times the camera effective pixel size

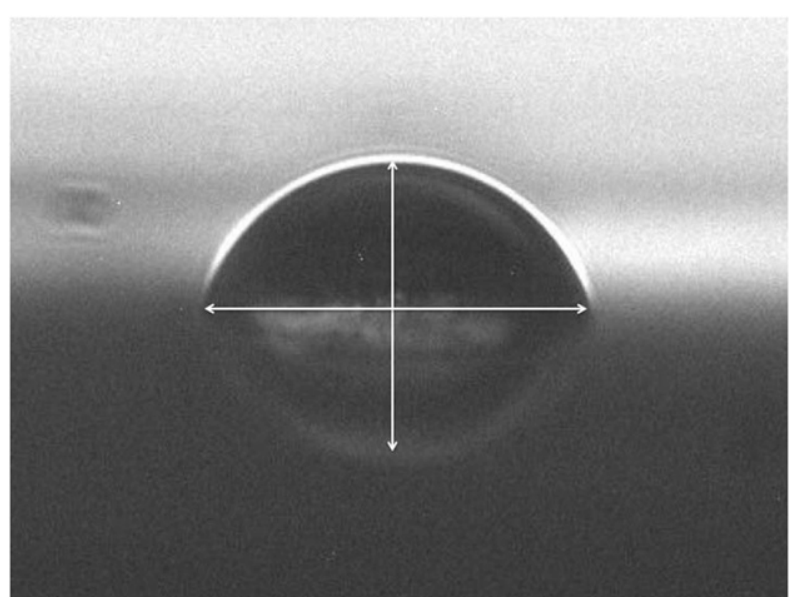

FIG. 10. Side image of spherical cap drop from slide 20 exposed on 23 Oct 2008 during the VOCALS project. The cap is reflected in the slide to make the bottom half a mirror image.

$(0.37 \mu \mathrm{m})$, and the microscope optics resolution is approximately two pixels.

\section{Determination of soluble mass}

The second microscope viewing nearly horizontally $\left(3^{\circ}\right)$ was used to obtain the image shown in Fig. 10. The profile image shows a spherical cap drop nearly in profile and also a reflected image from the surface of the polycarbonate slide.

Figure 11 shows geometric parameters for a spherical cap. A total of 164 side-looking digital images were used to obtain pairs of $2 h$ (the distance from the top of the spherical cap to the bottom of the reflection in the glass, see vertical arrow in Fig. 10) and $2 r_{b}$ (side-to-side measurement of the spherical cap), see horizontal arrow in Fig. 10, after which the average spherical cap aspect ratio, $\bar{A}=\bar{h} / r_{b}$, can be determined. The value of $A$ shows some variability for the 164 images from 7 slides that were manually digitized; see the histogram of $h / r_{b}$ in Fig. 12. The mean ratio of $h / r_{b}$ is 0.85 with a standard deviation of 0.09 ; the mean value corresponds to a contact angle of about $81^{\circ}$, which is very close to the measured contact angle of pure water on polycarbonate (Accu Dyne Test 2019). The standard deviation of 0.09 may be due to surface inhomogeneities on the slide (less likely), to focus shifts and measurement errors, or to actual variations in surface tension of hydrated sea-salt aerosols (more likely, see Fig. 5). The latter could be caused by variations in organic surfactants on the aerosols. The average value of $h / r_{b}=0.85$, suitable for polycarbonate slides, is used in all subsequent calculations of the volume of spherical cap drops. The implication is that only $r_{b}$ need to be determined for 


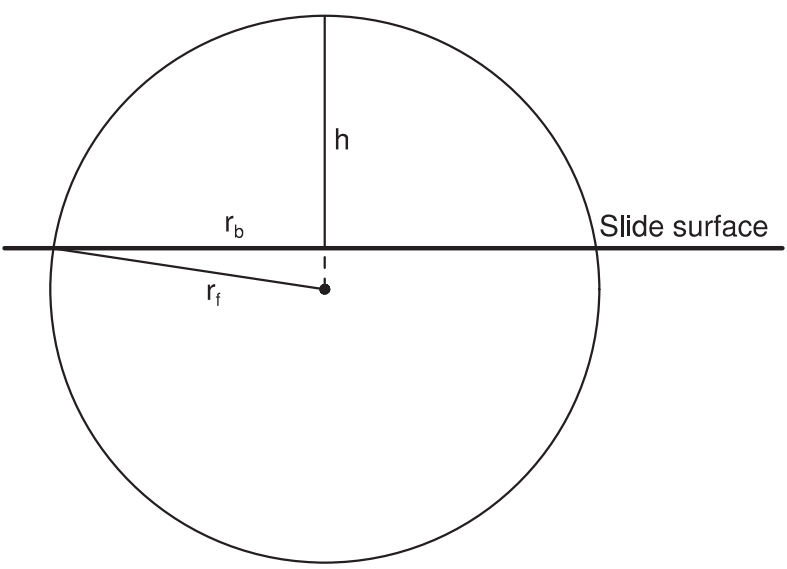

FIG. 11. Geometry and variables used for the spherical cap calculation. The distance from the slide surface to the top of the spherical cap is $h$, and the radius of the base of the spherical cap is $r_{b}$. The spherical cap is part of a sphere with radius $r_{f}$. The spherical cap shown has an aspect ratio of $h / r_{b}=0.85$.

each particle (using the vertical microscope column) in order to calculate the volume of the spherical cap drop.

From the radius of the base of the spherical cap $\left(r_{b}\right)$ and the above mean ratio of $h / r_{b}$, the height $(h)$ of the spherical cap drop can be calculated. The volume of the spherical cap ( $\left.V_{\text {cap }}\right)$ is given by (see also Fig. 11)

$$
V_{\text {cap }}=\frac{\pi h}{6}\left(3 r_{b}^{2}+h^{2}\right) \text {. }
$$

For the rhs of the equation, see Harris and Stocker (1998, section 4.8.4).

From this volume, we can calculate the radius of a sphere $\left(r_{c}\right)$ with the same volume as the spherical cap:

$$
r_{c}=\left(\frac{3 V_{\text {cap }}}{4 \pi}\right)^{1 / 3}
$$

The spherical cap forms part of larger sphere, with radius $r_{f}$ (Fig. 11) given by

$$
r_{f}=\frac{r_{b}^{2}+h^{2}}{2 h} .
$$

Based on Köhler theory, the mass of salt in the large sphere $\left(m_{\mathrm{sf}}\right)$ can be calculated as shown in the next section. Subsequently, the mass of salt $\left(m_{s}\right)$ in the impacted particle is calculated by scaling with the volumes:

$$
m_{s}=\frac{r_{c}^{3}}{r_{f}^{3}} m_{\mathrm{sf}}
$$

\section{a. Sea-salt dry radius calculation}

We assume that all qualifying round particles (when viewed from above) consist of sea salt. For sea salt in

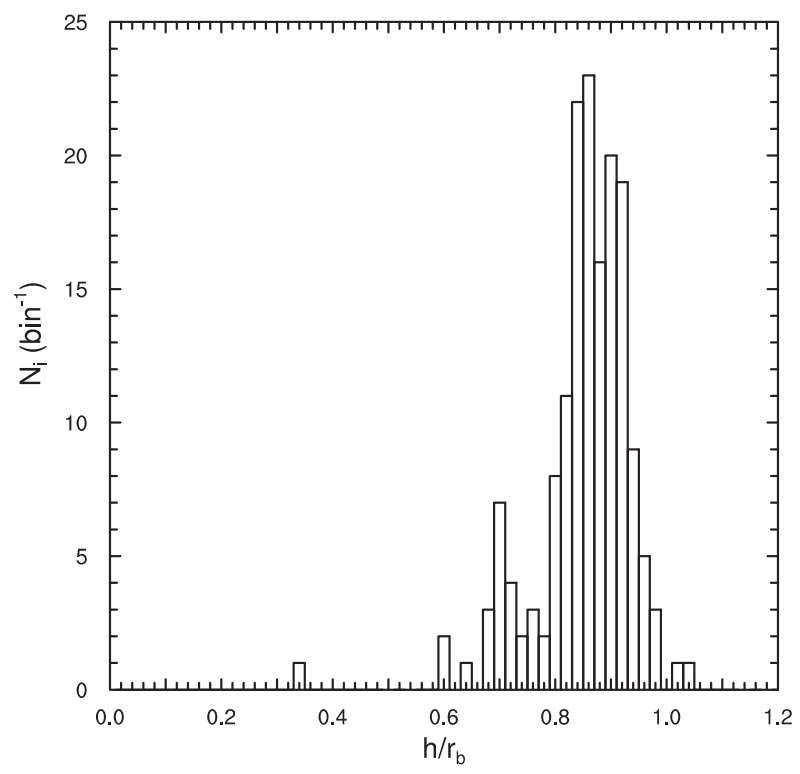

FIG. 12. Count histogram of $h / r_{b}$ for manually analyzed spherical cap drops. The mean cap aspect ratio is 0.85 and the standard deviation is 0.09 .

ocean water, the mole fraction of $\mathrm{Na}$ and $\mathrm{Cl}$ exceeds $90 \%$ of all sea-salt ions (Lewis and Schwartz 2004). Tang et al. (1997) have shown that the sizes of deliquesced seasalt aerosols have hygroscopic behavior almost identical to those of $\mathrm{NaCl}$ particles for relative humidity values of $48 \%$ to more than $90 \%$, and that sea salt may exist as solution droplets at larger than $45 \%$ relative humidity. More recently Zieger et al. (2017) have argued that the hygroscopic growth of sea salt is $8 \%-15 \%$ less that of pure $\mathrm{NaCl}$. In the present study, we consider dry salt mass to be that of anhydrous salt; i.e., in contrast to Zieger et al. (2017) we exclude the amount of water bound in crystals as hydrates (e.g., $\mathrm{MgCl}_{2}$ hexahydrate and $\mathrm{Na}_{2} \mathrm{SO}_{4}$ decahydrate). Hence for the GNI analyzed particles, we calculate the dry aerosol mass and dry radius based on a sea-salt composition in accordance with Tang et al. (1997).

For a known $r_{f}$ [see Eq. (7)], chamber saturation ratio $\left(S_{c}\right)$ and assumed chemical composition (sea salt), we can determine the sea-salt mass $\left(m_{\mathrm{sf}}\right)$ in a given particle from the Köhler equation (Pruppacher and Klett 1978):

$$
\ln S_{c}=\frac{2 \sigma_{\mathrm{so}}}{R_{v} T_{c} \rho_{w} r_{f}}-\frac{\nu \Phi m_{\mathrm{sf}} M_{w}}{M_{s}\left(\frac{4 \pi}{3} r_{f}^{3} \rho_{\mathrm{so}}-m_{\mathrm{sf}}\right)} .
$$

Here $\sigma_{\text {so }}$ is the surface tension of sea-salt solution against air, $R_{v}$ the gas constant for water vapor, $T_{c}$ the chamber temperature, $\rho_{w}$ and $\rho_{\text {so }}$ the densities of water and sea-salt solution, $\nu$ the number of ions the salt 
molecule can dissociate into, $\Phi$ the practical osmotic coefficient, and $M_{w}$ and $M_{s}$ the molar weights of water and sea salt, respectively.

Whereas this is the full Köhler equation, here given in a form often used in the cloud physics literature, we can simplify it with little error. First, for dry sea-salt radii in excess of $0.7 \mu \mathrm{m}$ (the smallest analyzed particle size with the present GNI microscope), the surface tension term [first term on the rhs of Eq. (9)] is negligible in comparison with the solution term [second term on the rhs of Eq. (9)] for the microscope chamber saturation $S_{c} \approx 0.9$. Approximating the sea-salt drops as pure $\mathrm{NaCl}$ and omitting the surface tension term leads to less than a $0.2 \%$ error in the determination of the dry $\mathrm{NaCl}$ particle radius (for $r_{d}=0.7 \mu \mathrm{m}$ ), with the error decreasing with increasing $\mathrm{NaCl}$ dry radius. This less than $0.2 \%$ error was determined by iterative solutions of Eq. (9) with and without the surface tension term.

By omitting the surface tension term, Eq. (9) for the full sphere with radius $r_{f}$ and sea-salt mass $m_{\mathrm{sf}}$ can be simplified to

$$
S_{c} \approx a_{w}=\exp \left[-\frac{\nu \Phi m_{\mathrm{sf}} M_{w}}{M_{s}\left(\frac{4 \pi}{3} r_{f}^{3} \rho_{\mathrm{so}}-m_{\mathrm{sf}}\right)}\right],
$$

where $a_{w}$ is the water activity (that is the ratio of equilibrium vapor pressure over a salt solution, relative to the equilibrium vapor pressure over pure water, both for a plane liquid surface).

With the same simplification, we can write Eq. (10) for the impacted particle (the spherical cap part of the full sphere) with radius $r_{c}$ [Eq. (6)] and salt mass $m_{s}$ as

$$
S_{c} \approx a_{w}=\exp \left[-\frac{\nu \Phi m_{s} M_{w}}{M_{s}\left(\frac{4 \pi}{3} r_{c}^{3} \rho_{\text {so }}-m_{s}\right)}\right] .
$$

However, Eq. (11) must be solved iteratively for $m_{s}$, so instead the following procedure will be used to determine the sea-salt mass in each spherical cap drop.

Using a known sea-salt particle mass, a hygrometer, and an electrodynamic balance to ensure that suspended sea-salt solution droplets were in equilibrium, Tang et al. (1997) obtained measurements of water activity $\left(a_{w}\right)$ for seawater (sea-salt) solutions of different strengths. Tang et al. (1997) use a polynomial fit equation [their Eq. (1)] and values in their Table 2, to give water activity as a function of soluble weight percentage (salt mass divided by total solution mass, times 100). They also give a similar
TABLE 3. Polynomial expression for mass fraction of sea salt $(\chi)$ in a water solution as a function of water activity; see Eq. (12).

\begin{tabular}{cc}
\hline \hline Polynomial coefficient & Value \\
\hline$c_{0}$ & $-0.193872 \times 10^{-2}$ \\
$c_{1}$ & $0.207282 \times 10^{1}$ \\
$c_{2}$ & $-0.762111 \times 10^{1}$ \\
$c_{3}$ & $0.207639 \times 10^{2}$ \\
$c_{4}$ & $-0.295281 \times 10^{2}$ \\
$c_{5}$ & $0.172937 \times 10^{2}$ \\
\hline
\end{tabular}

polynomial for the density of the solution as a function of soluble weight percentage.

However, in the present GNI microscope case, we know $S_{c}$ and thus $a_{w}$, but we need to calculate the mass fraction of sea salt $(\chi)$ in each spherical cap drop, i.e., the inverse situation of Tang et al. (1997). Thus from Tang et al.'s (1997) polynomial expression [their Eq. (1)], we create a table of values of sea-salt mass fraction $(\chi)$ and water activity $\left(a_{w}\right)$. A polynomial fit,

$$
\chi=\sum_{n=0}^{5} c_{n}\left(1-a_{w}\right)^{n},
$$

to the tabled values, is used to obtain $\chi$ as a function of $a_{w}$; see Table 3. Thus based on the microscope measured radius of the base of the spherical cap droplets $\left(r_{b}\right)$ and the average aspect ratio of spherical cap drops $\left(h / r_{b}=\right.$ $0.85)$, we can calculate the volume of the spherical cap drop [ $V_{\text {cap }}$; Eq. (5)]. For a known saturation ratio in the slide chamber $\left(S_{c}\right)$, by neglecting curvature effects $\left(S_{c} \approx\right.$ $a_{w}$ ), and under the assumption of sea salt in the spherical cap droplets, we can calculate the sea-salt mass fraction [ $\chi$; Eq. (12)] in each spherical cap solution drop. The density of the sea-salt solution $\left(\rho_{\mathrm{so}}\right)$ in the spherical cap drops, is a function of $\chi$ and can be calculated based on Eq. (1) in Tang et al. (1997) and using their Table 2 coefficients. Thus, the total mass $\left(m_{t}\right)$ of each spherical cap droplet is

$$
m_{t}=V_{\mathrm{cap}} \rho_{\mathrm{so}},
$$

from which the mass of sea salt in each spherical cap drop can be determined from

$$
m_{s}=\chi m_{t} .
$$

From

$$
m_{s}=\frac{4 \pi}{3} r_{d}^{3} \rho_{s}
$$

where $\rho_{s}=2200 \mathrm{~kg} \mathrm{~m}^{-3}$ is the density of dry (anhydrous) sea salt (Lewis and Schwartz 2004), we can solve Eq. (15) for the dry sea-salt mass in an impacted aerosol particle by 


$$
r_{d}=\left[\frac{\chi h\left(3 r_{b}^{2}+h^{2}\right) \rho_{\mathrm{so}}}{8 \rho_{s}}\right]^{1 / 3} .
$$

Here we have used Eqs. (14), (13), and (5). In addition we make use of the relationship between water activity and sea-salt mass fraction in a solution drop [Eq. (12)], the Tang et al. (1997) expression for sea-salt solution density, and our empirical relationship between spherical cap height and radius of base $\left(h / r_{b}=0.85\right)$. Equation (16) is the key equation to relate the microscope determined spherical cap base size to sea-salt dry radius. At a relative humidity of $90 \%$, the ratio of dry radius $\left(r_{d}\right)$ to spherical cap base radius $\left(r_{b}\right)$ is about 0.30 .

\section{b. Sizing effects due to high microscope cabinet temperature}

The microscope cabinet is kept at a steady $33.7^{\circ} \mathrm{C}$, whereas Tang et al. (1997) measured drop properties at $25^{\circ} \mathrm{C}$; this leads to small differences in the solution density and mass fraction, relative to the Tang et al. (1997) conditions.

Based on the Pitzer et al. (1983) calculation of $\mathrm{NaCl}$ density as a function of temperature (their Table A-15; $3.0 \mathrm{~mol} \mathrm{~kg}^{-1} \mathrm{NaCl}$ solution), we estimate that the density of a $\mathrm{NaCl}$ solution is $0.36 \%$ lower at $T=33.7^{\circ} \mathrm{C}$ than at the Tang et al. (1997) temperature of $25^{\circ} \mathrm{C}$. Given that sea-salt and $\mathrm{NaCl}$ are similar, the GNI calculation presented here likely results in an overestimate of $0.12 \%$ in the calculated dry aerosol radius. We have omitted this effect in our calculations due to the small magnitude.

For a given sea salt mass fraction, the water activity in the $33.7^{\circ} \mathrm{C}$ microscope chamber differs from that of the Tang et al. (1997) measurements at $25^{\circ} \mathrm{C}$. Using the water activity data as a function of temperature from Bromley et al. (1974, their Table 5b), we linearly extrapolate from their minimum water activity of $a_{w}=0.924$ to the microscope chamber $a_{w} \approx 0.90$. This result in the GNI system overestimating the dry sea-salt radius by only $0.13 \%$; thus, we have omitted any correction for this small error.

\section{Sample volume and calculation of particle distributions}

The state of sea-salt aerosol particles depends both on the ambient relative humidity and, in some cases, on the history of relative humidity. It is well known that dry $\mathrm{NaCl}$ particles deliquesce once the humidity increases beyond a value of about $75 \%$ (e.g., Tang et al. 1997). However, sea-salt particles consist of a range of different salts, each with their own deliquescence point. Such aerosols may also contain smaller amounts of other chemical components, e.g., hydrates, organics, and sulfates, such that a sharp deliquescence point does not exist; see Fig. 1 in Tang et al. (1997). However, the Tang et al. (1997) study shows sea salt having complete deliquescence above $74 \%$ relative humidity, and in air with decreasing relative humidity, sea-salt drops may remain in solution well past the $74 \%$ deliquescence point, even to as low relative humidity as $45 \%$.

The assumption of deliquescence is necessary for the calculation of impaction efficiency between particles and microscope slides, which in turn affects the calculated "effective" sample volume for the impaction slides. The processing of the GNI slides and subsequent application of the data thus differs for three humidity regimes: (i) In air with relative humidity below $45 \%$ (based on Tang et al. 1997), sea-salt particles are assumed dry, but their shape and thus impaction efficiency is ill defined. Thus, slides exposed at less than $45 \%$ relative are excluded from further analysis. (ii) In air with relative humidity in excess of $74 \%$ (again based on Tang et al. 1997), sea-salt particles are assumed to be deliquesced solution drops. Accordingly, the GNI computer code calculates particle sizes and concentrations based on deliquesced particles. (iii) For air with intermediate relative humidity between $45 \%$ and $74 \%$, the GNI computer code calculates sizes and concentrations assuming deliquesced particles. However, users of the data must evaluate if slides exposed at these intermediate relative humidity were deliquesced at the time of impaction. A well-mixed marine boundary layer, with saturated air at the top, will have a depth of more than $1400 \mathrm{~m}$ in order to have $45 \%$ relative humidity just above sea surface; marine mixed layers are commonly less deep, and thus sea-salt particles in marine mixed layers can normally be assumed to be solution drops.

Assuming deliquesced particles and for ambient saturation ratio $S_{a}$ just prior to impaction, we next calculate the ambient drop radius $r_{a}$ for a given dry sea-salt radius $r_{d}$. The mass of a dry sea-salt aerosol $m_{s}$ is given by

$$
m_{s}=\frac{4 \pi}{3} r_{d}^{3} \rho_{s}
$$

where $\rho_{s}$ is the density of dry sea salt.

For a known $a_{w} \approx S_{a}$, the fraction of sea-salt mass $(\chi)$ in an ambient solution drop aerosol particle can be calculated from Eq. (12). Thus, the mass of the entire solution drop at ambient conditions is then given by

$$
m_{\text {drop }}=\frac{m_{s}}{\chi} .
$$

From a known $\chi$, the solution drop density $\rho_{\text {so }}$ is calculated using the Tang et al. (1997) relationship. 
Finally, the ambient solution drop radius at equilibrium is given by

$$
r_{a}=\left[\frac{3}{4 \pi} \frac{m_{\mathrm{drop}}}{\rho_{\mathrm{so}}}\right]^{1 / 3}
$$

This ambient radius is subsequently used in calculating impaction efficiency between particles and the GNI slides.

For an aerosol particle of dry radius $r_{d}$, after moistening it to its equilibrium size at $S_{a}$, the impaction efficiency between aerosol particle and slide, $E\left(r_{d}, S_{a}\right)$, is implemented using the Ranz and Wong (1952) formulas for collisions between spheres and infinite ribbons. Figure 13 shows the impaction efficiency for spherical solution drops approaching the slide, assuming an airspeed of $105 \mathrm{~m} \mathrm{~s}^{-1}$. For each particle, we assume the Tang et al. (1997) values for sea-salt solution drop density $\rho_{\mathrm{so}}$, and the calculations are performed using the true airspeed. For a $50 \%$ ambient relative humidity, the result is that particles of $1.1 \mu \mathrm{m}$ ambient radius have a $50 \%$ impaction efficiency. Thus, for relative humidity of $50 \%$ or higher, this implies that salt particles with $0.7 \mu \mathrm{m}$ dry radius are captured at $50 \%$ or higher efficiency. For moister environments, the GNI instrument can capture particles with smaller values of dry radius. For these reasons, we provide GNI based sea-salt dry radius size distributions for $r_{d}>0.7 \mu \mathrm{m} .^{1}$

The calculated sample volume of a microscope slide $V\left(r_{d}\right)$ is then

$$
V\left(r_{d}\right)=t U F_{\mathrm{enh}} N \operatorname{LHE}\left(r_{d}, S_{a}\right) \beta_{i},
$$

where $t$ is the slide exposure time in the free airstream, $U$ is the airspeed, $F_{\text {enh }}$ is a concentration factor to account for airflow accelerating around the aircraft fuselage and particle concentrating due to cross-streamline motion in the air around the aircraft (King 1984; see below), $N=350$ is the number of microscope images per slide, $L=592 \mu \mathrm{m}$ and $H=444 \mu \mathrm{m}$ are the individual image length and heights, and $\beta_{i}$ is a function that describes the reduction in sample area $(L \times H)$ for an individual image due to the requirement that a particle cannot touch the image edge:

$$
\beta_{i}=\frac{\left(N_{x}-1-n_{x}\right)\left(N_{y}-1-n_{y}\right)}{N_{x} N_{y}},
$$

\footnotetext{
${ }^{1}$ For nonspherical particles (e.g., clay minerals or bioaerosols), the collision efficiency will tend to be lower than that of sea-salt solution drops. For particles of higher density (e.g., other mineral dust), the collision efficiency will tend to be higher than for the similarly sized sea-salt solution drops. In the calculation of collision efficiencies, we do not consider electrical charge differences between the impacting aerosol particles and the polycarbonate slides.
}

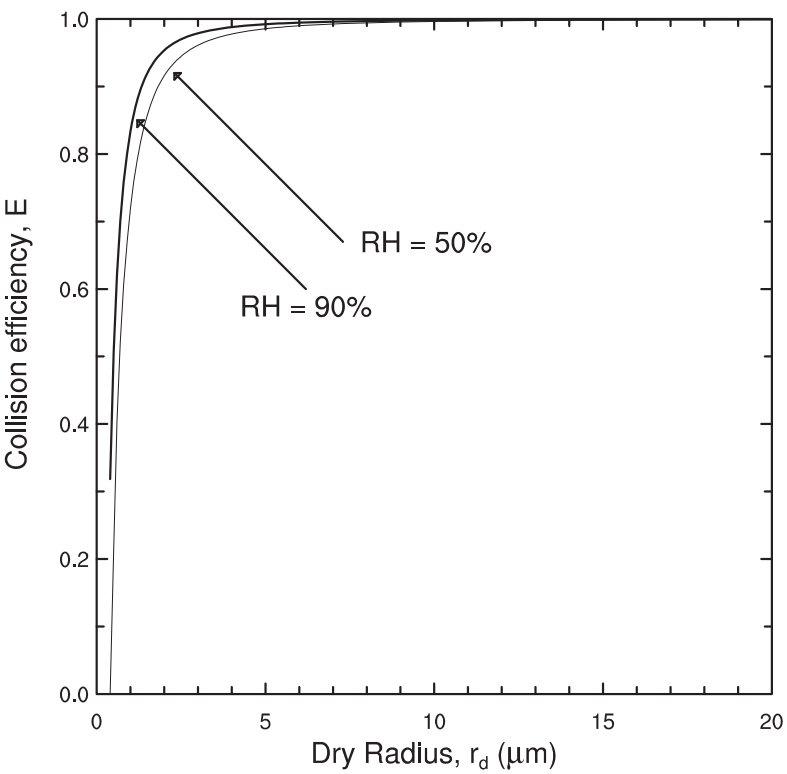

FIG. 13. Impaction efficiency for solution droplets at relative humidities of $50 \%$ and $90 \%$ as a function of the dry sea-salt radius. The $50 \%$ impaction efficiency occurs for dry sea-salt radii of 0.7 and $0.5 \mu \mathrm{m}$ and for solution drop sizes of 1.1 and $1.2 \mu \mathrm{m}$, respectively, for the two relative humidities. The calculations pertain to droplets moving at $105 \mathrm{~m} \mathrm{~s}^{-1}$ toward a ribbon of $6.37 \mathrm{~mm}$ width, following Ranz and Wong (1952). Other conditions are $1000 \mathrm{hPa}$ pressure, $15^{\circ} \mathrm{C}$ temperature, and a $105 \mathrm{~m} \mathrm{~s}^{-1}$ true airspeed.

where $N_{x}=1600$ and $N_{y}=1200$ are the number of pixels for the $x$ and $y$ directions of the digital camera chip, and $n_{x}$ and $n_{x}$ are the maximum number of shaded particles in the two image directions for each analyzed particle. For particle dry radii of 0.7 and $10 \mu \mathrm{m}$, the correction factor $\beta_{I}$ has values of 0.98 and 0.75 , respectively.

The concentration enhancement factor has been determined through potential flow modeling by King (1984) to be

$$
F_{\mathrm{enh}}=1+\frac{b}{-4.34 b N_{\mathrm{st}}^{0.267}+38.1 d N_{\mathrm{st}}^{-0.30}},
$$

where $b$ is the aircraft fuselage radius (about $1.8 \mathrm{~m}$ for the C-130), $d$ is the distance of the impaction slide from the fuselage, $N_{\mathrm{st}}$ is a modified particle Stokes parameter [see King 1984, their Eq. (29)],

$$
N_{\mathrm{st}}=\frac{2 r_{a}^{2} U \rho_{\mathrm{so}}}{9 \eta b}
$$

where $r_{a}$ is the solution droplet ambient radius, $U$ the aircraft true airspeed, $\rho_{\text {so }}$ the density of the solution drop, and $\eta$ the dynamic viscosity of air. A characteristic of the potential flow solution is that the calculation does not include a boundary layer. This boundary layer is 
expected to be about $80 \mathrm{~mm}$ thick at the position of the GNI slide strut on the C-130 (Lord 2019, personal communication). Accordingly, for the value of $d$ we use $520 \mathrm{~mm}$, as opposed to the actual $600 \mathrm{~mm}$. At an airspeed of $U=105 \mathrm{~m} \mathrm{~s}^{-1}, 70 \%$ relative humidity, and for dry sea-salt radii of $r_{a}=2,4$, and $8 \mu \mathrm{m}$, the concentration enhancement factor amounts to increases of $2.5 \%, 4 \%$, and $6.5 \%$, respectively.

A slide with 350 images $\left(92 \mathrm{~mm}^{2}\right.$ total area) samples about $10 \mathrm{Ls}^{-1}$ at an airspeed of $105 \mathrm{~m} \mathrm{~s}^{-1}$, assuming a theoretical impaction efficiency of unity. During VOCALS exposure times were selected based on assumed aerosol loading to range typically from 5 to $15 \mathrm{~s}$ (more rarely $30 \mathrm{~s}$ ) when flying below $1000 \mathrm{~m}$ altitude. The corresponding sample volumes are thus about $0.05-0.15 \mathrm{~m}^{3}$ (more rarely $0.3 \mathrm{~m}^{3}$ ) for the various low-altitude slides collected during the VOCALS project.

\section{Control slides and other effects}

Contamination of the polycarbonate slides in preparation and handling is a potential problem. To measure the severity of contamination, control slides were taken on sampling missions. The control slides were prepared along with the normal slides, and mounted and put into the slide pod, but not exposed to the free airstream outside the aircraft. By analyzing these control slides, we can estimate the average amount of contamination in preparation and handling of the actual slides. This also establishes a baseline by requiring that actual particle measurements must be in excess of those measured from the control slides. For the VOCALS field program, more than 30 control slides were examined. It was determined that the polycarbonate slides were exceptionally clean, to an extent that it was almost impossible to find any particles to focus on. The result was that it was not necessary to correct VOCALS slides for handling contamination.

Breakup of solution drops impacting on the slide during exposure has potentially serious implications for the measurement of size distributions. This problem is not limited to the slides exposed as part of the GNI instrument; it is a common problem even for optical probes designed to measure cloud particles from aircraft (e.g., Vidaurre and Hallett 2009; Baker et al. 2009). Impaction effects for deliquesced sea-salt drops are examined statistically in Part II, where it is demonstrated that these have only a small effect on the measured size distributions. While deliquesced sea-salt particles appear likely to stick to the slides after impact, it is at present unclear if, e.g., mineral dust and bioaerosols may bounce off after impaction. While the GNI code can size such particles, we are thus uncertain about determining size distributions of these. Part II also provides

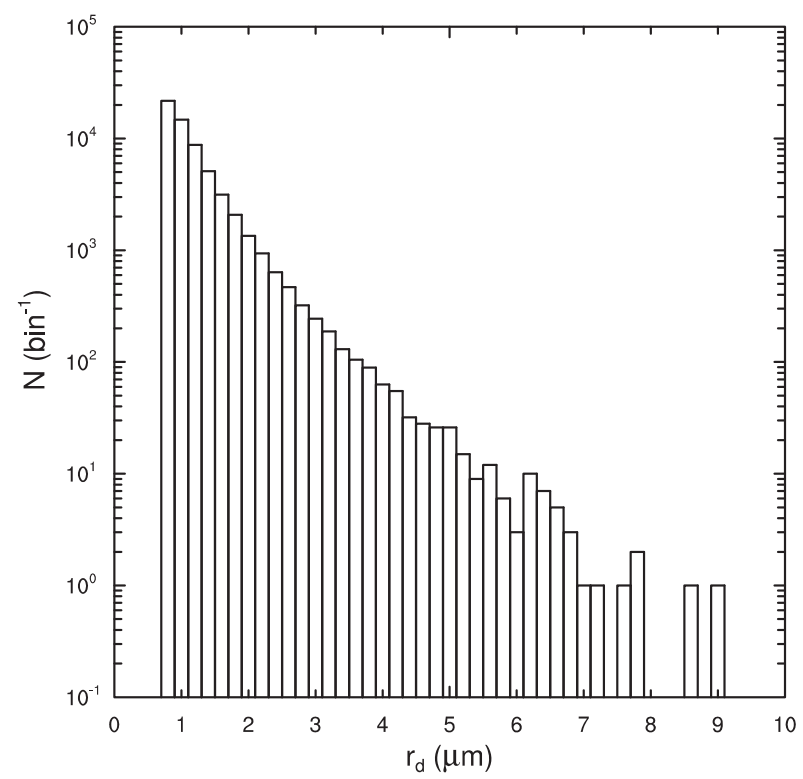

FIG. 14. Count histogram of dry sea-salt radius $\left(r_{d}\right)$ for all the round particles collected from slide 3 on 10 Oct 2008 off the coast of Chile. The relative humidity was $70 \%$ at the time exposure.

a comprehensive uncertainty analysis for the GNI system when applied to deliquesced sea-salt aerosol particles.

\section{Example size distribution}

Figure 14 shows an example of a dry aerosol size distribution observed on a low-wind speed day during the VOCALS project. It should be noted that the total count of giant aerosol particles $\left(r_{d}>0.7 \mu \mathrm{m}\right)$ is about 60000 for the 350 images of the slide; i.e., the sampling statistics are exceptionally good out to $5 \mu \mathrm{m}$ dry radius, and a considerable number of particles between 5 and $9 \mu \mathrm{m}$ dry radius are also observed. There is a drop-off in the count of particles for the smallest particles; the Ranz and Wong (1952) 50\% collision efficiency occurs at $1.1 \mu \mathrm{m}$ ambient radius, corresponding to about $0.6 \mu \mathrm{m}$ dry radius. The GNI measured size distributions are typically near-lognormal, see the example in Blot et al. (2013).

In Fig. 15 the same data are plotted as cumulative size distribution to facilitate a comparison with Woodcock's (1953) measurements. The VOCALS sample was obtained at an altitude of $150 \mathrm{~m}$ and $5.4 \mathrm{~m} \mathrm{~s}^{-1}$ ambient wind speed. The comparable surface ( $10 \mathrm{~m}$ altitude) wind speed is about $4-5 \mathrm{~m} \mathrm{~s}^{-1}$. In this example, the VOCALS results show about a factor-of-3-higher concentrations than those Woodcock found, but for a given wind speed, Lewis and Schwartz (2004) state typical natural variability of a factor 3 around their "canonical" size distributions. Woodcock (1953) also sampled his slides right below cloud base, and it is possible that there 


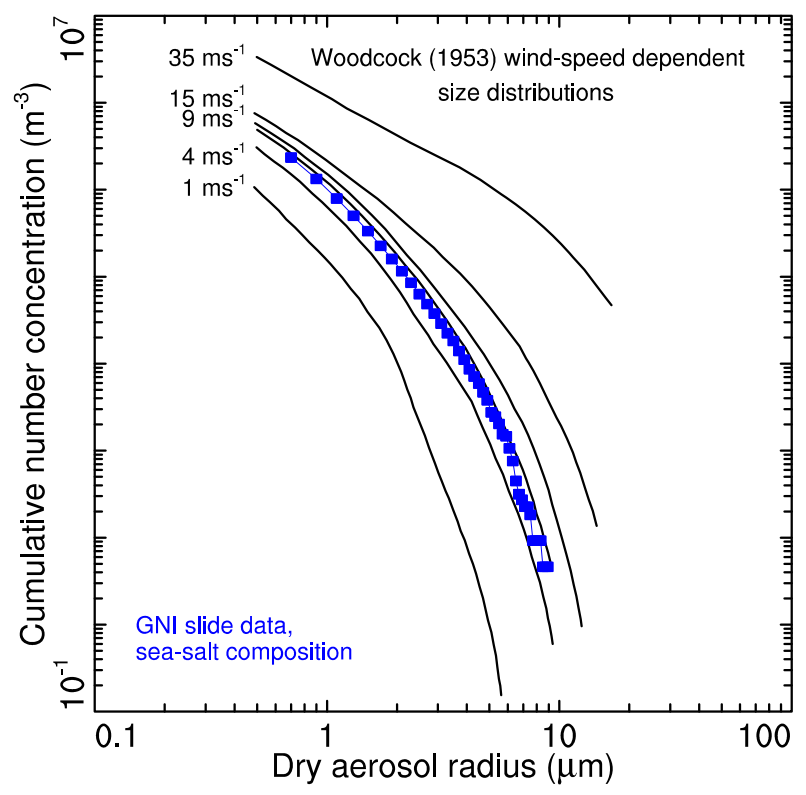

FIG. 15. As in Fig. 14, but for size distribution in cumulative form. The Woodcock (1953) size distributions are also included for comparison. Woodcock showed size distributions with dry radius smaller than about $1 \mu \mathrm{m}$ dashed, presumably to denote higher uncertainty. The VOCALS slide was exposed at an average ambient wind speed of $5.4 \mathrm{~m} \mathrm{~s}^{-1}$ at $150 \mathrm{~m}$ altitude. The Simpson (1906) expression has been used to convert from Woodcock's use of Beaufort wind force to wind speed.

is a gradient in giant aerosol concentrations from our measurements at $150 \mathrm{~m}$ toward Woodcock's measurements about $500 \mathrm{~m}$ higher.

To conclude, the GNI instrument and analysis give results that appear to be comparable to measurements previously published by Woodcock (1953) using a very similar method. Whereas this is satisfying, we note that the present GNI instrument is vastly improved, that the capacity of the present system far exceeds that of Woodcock (1953) by allowing for analysis of 40 slides in a batch and by sizing a factor 100 (approximately) more on each slide (typically tens of thousands particles on each GNI slide versus hundreds; see his Tables 2 and 3), and that the time of analysis per particle is likely shortened by several orders of magnitude. This makes it feasible to study smaller-scale aerosol variability, for example as affected by cloud processing, and it also lowers the uncertainty in measured size distributions of salt particles.

\section{Summary}

A new automated analysis system, the GNI instrument, has been developed to facilitate the automatic, humidity-controlled sizing of giant and ultragiant aerosol particles that have been impacted on microscope slides. These slides were exposed from aircraft in the free airstream outside the aircraft, as opposed to capture through an inlet. The following are features of the GNI:

- The system is capable of sampling very large volumes in a short time period, typically $10 \mathrm{Ls}^{-1}$ when sampling from an aircraft flying at about $105 \mathrm{~m} \mathrm{~s}^{-1}$. This makes it suited for sampling of very large particles, which occur in low concentrations. The total number of particles sized on each slide far exceeds the number used in many previous studies. On most of the VOCALS slides, the number of sized giant aerosol particles were usually on the order of tens of thousands.

- For a 6.37-mm-wide slide exposed at aircraft speeds $\left(105 \mathrm{~m} \mathrm{~s}^{-1}\right)$, the $50 \%$ impaction efficiency occurs for dry sea-salt radii of 0.7 and $0.5 \mu \mathrm{m}$ (corresponding to solution drop sizes of 1.1 and $1.2 \mu \mathrm{m}$ ), for ambient relative humidities of $50 \%$ and $90 \%$, respectively. For aerosol particles of different geometric shapes or densities, compared to the present sea-salt solution drops, the $50 \%$ impaction size may differ.

- Slides are analyzed using a microscope with a digital camera and a two-axis motorized stage. A third motor drive in combination with a focus algorithm is used to find the focal plane, thus ensuring images are in focus. The minimum detectable size is estimated to be smaller than $0.5 \mu \mathrm{m}$ dry radius when analyzed at $90 \%$ relative humidity. The particles are sized with a bin width of $0.2 \mu \mathrm{m}$ dry radius, which is comparable to the microscope optical resolution when accounting for deliquescence of the aerosol particles. For conditions in typical marine boundary layers, the size distributions of sea-salt particles can be calculated for particles with $r_{d}>0.7 \mu \mathrm{m}$. The maximum observed particle size is $16 \mu \mathrm{m}$ dry radius.

- The system is particularly well suited to the analysis of sea-salt particles. By maintaining the relative humidity at about $90 \%$, almost all soluble particles form spherical cap drops. Turning sea-salt particles into solution drops also allows for detection of smaller salt particles, as soluble particles swell with water uptake. This makes small particles detectable by the microscope.

- Particles are sized using a pixel shading threshold, by finding the center of gravity from the perimeter pixels, and then by calculating the distance from the center of gravity to the perimeter, using 64 angles. Round particles are assumed to be sea salt. Simple spherical cap geometry, in conjunction with Köhler theory and prior laboratory studies, is used to determine the dry sea-salt mass, and thus the dry aerosol particle radius.

- Control slides are used to estimate the amount of contamination in preparation and handling of the slides. Comparison of many sample and control slides show that contamination is insignificant. 
- The GNI system allows for analysis of giant aerosol particles on a large scale. This is due to the microscope system being able to handle 40 slides per batch. This allows for a much better characterization of giant aerosol particles (coarse mode particles) than previously possible. As an example, during the 2008 VOCALS project in excess of 450 slides were exposed in and above the marine boundary layer. Each of these slides required about $3 \mathrm{~h}$ for image acquisition in the microscope system, and about $3 \mathrm{~h}$ for dry radius determination using a computer workstation.

Sampling from aircraft using high-speed impaction leads to some problems due to impact splashing and coalescence on the slide (see Part II). Other sampling methods from aircraft using air intakes and connecting tubes have other types of problems associated with turbulence and losses of particles to tube walls, including a gradual buildup of salt. The present GNI system uses a clean slide at the start of every sampling event; thus, every slide behaves identically.

Giant aerosols can also be sampled at lower speeds with the GNI instrument, possibly from kites, from towers, and from other ground sites, provided the wind speed is sufficiently high and well characterized. The exposed slides can also be used for particle analysis using, e.g., electron microscopy for single particle ion composition, although such analysis is not part of the GNI microscope system.

When impacting other particle types than sea-salt solution droplets (e.g., mineral dust and oceanic biogenic particles), it is possible that particle bounce is more severe, thus possibly biasing the measured particle size distribution toward sea salt. Some of the observed droplets, in particular the larger ones, contain enclosed material that looks like biogenic or shell material. However, these particles are typically surrounded by a much larger mass of sea-salt solution. This is consistent with bubble bursting leading to jet droplet formation, that happened to have biogenic or shell material included already at the formation of the jet droplet.

Acknowledgments. This material is based upon work supported by the National Center for Atmospheric Research, which is a major facility sponsored by the National Science Foundation under Cooperative Agreement 1852977. The development of the present instrument was in part funded by a grant from the NCAR Director's Instrument Fund. The development of a prototype instrument was done with support from the Cape Grim Baseline Air Pollution Station, Australia. Part of this work was done while J. Jensen was employed by CSIRO, Australia, and serving as a visiting scientist at NCAR. R. Rauber and M. Colón Robles were supported under
National Science Foundation Grants NSF-ATM-03-46172 and NSF-ATM-0854954. Thanks are due to Dr. William A. Cooper, Dr. Charlie Knight, and two anonymous reviewers for many excellent comments. Thanks is due to Dr. Aaron Bell (Department of Geology, University of Colorado) for elemental analysis of some impacted particles.

Data availability statement. The raw GNI image data are available from NCAR/EOL at https://doi.org/10.5065/ D6NZ862W. Please contact jbj@ucar.edu for assistance.

\section{REFERENCES}

Accu Dyne Test, 2019: Critical surface tension and contact angle with water for various polymers. Diversified Enterprises, https:// www.accudynetest.com/polytable_03.html.

Andreae, M. O., and D. Rosenfeld, 2008: Aerosol-cloud-precipitation interactions. Part 1 . The nature and sources of cloud-active aerosols. Earth-Sci. Rev., 89, 13-41, https://doi.org/10.1016/ j.earscirev.2008.03.001.

Apelblat, A., and E. Korin, 1998: Vapour pressures of saturated aqueous solutions of ammonium iodide, potassium iodide, potassium nitrate, strontium chloride, lithium sulphate, sodium thiosulphate, magnesium nitrate, and uranyl nitrate from $T=(278$ to 323$)$ K. J. Chem. Thermodyn., 30, 459-471, https:// doi.org/10.1006/jcht.1997.0311.

Arthur, D. K., S. Lasher-Trapp, A. Abdel-Halem, N. Klosterman, and D. S. Ebert, 2010: A new three-dimensional visualization system for combining aircraft and radar data and its application to RICO observations. J. Atmos. Oceanic Technol., 27, 811-828, https://doi.org/10.1175/2009JTECHA1395.1.

Baker, B., Q. X. Mo, R. P. Lawson, D. O'Connor, and A. Korolev, 2009: The effects of precipitation on cloud droplet measurement devices. J. Atmos. Oceanic Technol., 26, 1404-1409, https://doi.org/10.1175/2009JTECHA1191.1.

Blomquist, B. W., and Coauthors, 2001: An evaluation of the Community Aerosol Inlet for the NCAR C-130 research aircraft. J. Atmos. Oceanic Technol., 18, 1387-1397, https://doi.org/ 10.1175/1520-0426(2001)018<1387:AEOTCA > 2.0.CO;2.

Blot, R., and Coauthors, 2013: Ultrafine sea spray aerosol over the southeastern Pacific: Open-ocean contributions to marine boundary layer CCN. Atmos. Chem. Phys., 13, 7263-7278, https://doi.org/10.5194/acp-13-7263-2013.

Blyth, A. M., S. G. Lasher-Trapp, W. A. Cooper, C. A. Knight, and J. Latham, 2003: The role of giant and ultragiant nuclei in the formation of early radar echoes in warm cumulus clouds. J. Atmos. Sci., 60, 2557-2572, https://doi.org/10.1175/15200469(2003)060<2557:TROGAU > 2.0.CO;2.

Bolton, D., 1980: The computation of equivalent potential temperature. Mon. Wea. Rev., 108, 1046-1053, https://doi.org/ 10.1175/1520-0493(1980)108<1046:TCOEPT>2.0.CO;2.

Bromley, L. A., D. Singn, P. Ray, S. Sridhar, and S. M. Read, 1974: Thermodynamic properties of sea salt solutions. AIChE J., 20, 326-335, https://doi.org/10.1002/aic.690200218.

Cooper, W. A., R. T. Bruintjes, and G. K. Mather, 1997: Calculations pertaining to hygroscopic seeding with flares. J. Appl. Meteor., 36, 1449-1469, https://doi.org/10.1175/15200450(1997)036<1449:CPTHSW > 2.0.CO;2.

Cox, C. J., D. C. Noone, M. Berkelhammer, M. D. Shupe, W. D. Neff, N. B. Miller, V. P. Walden, and K. Steffen, 2019: Supercooled 
liquid fogs over the central Greenland ice sheet. Atmos. Chem. Phys., 19, 7467-7485, https://doi.org/10.5194/acp-19-7467-2019.

Dadashazar, H., and Coauthors, 2017: Relationships between giant sea salt particles and clouds inferred from aircraft physiochemical data. J. Geophys. Res. Atmos., 122, 3421-3434, https://doi.org/10.1002/2016JD026019.

Dagan, G., I. Koren, and O. Altaratz, 2015: Aerosol effects on the timing of warm rain processes. Geophys. Res. Lett., 42, 45904598, https://doi.org/10.1002/2015GL063839.

Feingold, G., W. R. Cotton, S. M. Kreidenweis, and J. T. Davis, 1999: The impact of giant cloud condensation nuclei on drizzle formation in stratocumulus: Implications for cloud radiative properties. J. Atmos. Sci., 56, 4100-4117, https://doi.org/10.1175/ 1520-0469(1999)056<4100:TIOGCC $>2.0$. CO;2.

Finlayson-Pitts, B. J., and J. N. Pitts, 2005: Atmospheric Chemistry: Fundamentals and Experimental Techniques. John Wiley, $1098 \mathrm{pp}$.

Freud, E., and D. Rosenfeld, 2012: Linear relation between convective cloud drop number concentration and depth for rain initiation. J. Geophys. Res., 117, D02207, https://doi.org/10.1029/ 2011JD016457.

Gerber, H. E., and G. M. Frick, 2012: Drizzle rates and large seasalt nuclei in small cumulus. J. Geophys. Res., 117, D01205, https://doi.org/10.1029/2011JD016249.

Geresdi, I., and R. Rasmussen, 2005: Freezing drizzle formation in stably stratified layer clouds. Part II: The role of giant nuclei and aerosol particle size distribution and solubility. J. Atmos. Sci., 62, 2037-2057, https://doi.org/10.1175/JAS3452.1.

Harris, J. W., and H. Stocker, 1998: Handbook of Mathematics and Computational Science. Springer, 107 pp.

Hindman, E. E., P. V. Hobbs, and L. F. Radke, 1977: Airborne investigations of aerosol-particles from a paper-mill. J. Air Pollut. Control Assoc., 27, 224-229, https://doi.org/10.1080/ 00022470.1977.10470414.

Hobbs, P. V., and A. L. Rangno, 2004: Super-large raindrops. Geophys. Res. Lett., 31, L13102, https://doi.org/10.1029/2004GL020167.

- D. A. Bowdle, and L. F. Radke, 1985: Particles in the lower troposphere over the High Plains of the United States. Part I: Size distributions, elemental compositions and morphologies. J. Climate Appl. Meteor., 24, 1344-1356, https://doi.org/10.1175/ 1520-0450(1985)024<1344:PITLTO > 2.0.CO;2.

Houghton, H. G., 1938: Problems connected with the condensation and precipitation processes in the atmosphere. Bull. Amer. Meteor. Soc., 19, 152-159, https://doi.org/10.1175/1520-0477-19.4.152.

Hudson, J. G., S. Noble, V. Jha, and S. Mishra, 2009: Correlations of small cumuli droplet and drizzle drop concentrations with cloud condensation nuclei concentrations. J. Geophys. Res., 114, D05201, https://doi.org/10.1029/2008JD010581.

Huebert, B. J., and Coauthors, 2004: PELTI: Measuring the passing efficiency of an airborne low turbulence aerosol inlet. Aerosol Sci. Technol., 38, 803-826, https://doi.org/ 10.1080/027868290500823.

Jensen, J. B., and S. Lee, 2008: Giant sea-salt aerosols and warm rain formation in marine stratocumulus. J. Atmos. Sci., 65 , 3678-3694, https://doi.org/10.1175/2008JAS2617.1.

— formed on giant sea-salt aerosol particles. J. Atmos. Sci., 74, 679-697, https://doi.org/10.1175/JAS-D-15-0370.1.

— data. National Center for Atmospheric Research, accessed 25 June 2019, https://doi.org/10.26023/ZJVK-ZMF2-VZ0V.

Johnson, D. B., 1976: Ultra-giant urban aerosol particles. Science, 194, 941-942, https://doi.org/10.1126/science.194.4268.941.
_ 1982: The role of giant and ultra giant nuclei in warm rain initiation. J. Atmos. Sci., 39, 448-460, https://doi.org/10.1175/ 1520-0469(1982)039<0448:TROGAU>2.0.CO;2.

Jung, E., and Coauthors, 2015: Precipitation effects of giant cloud condensation nuclei artificially introduced into stratocumulus clouds. Atmos. Chem. Phys., 15, 5645-5658, https://doi.org/ 10.5194/acp-15-5645-2015.

King, W. D., 1984: Air flow and particle trajectories around aircraft fuselages. I: Theory. J. Atmos. Oceanic Technol., 1, 5-13, https://doi.org/10.1175/1520-0426(1984)001<0005: AFAPTA $>2.0 . \mathrm{CO} ; 2$.

Knight, C. A., L. J. Miller, and R. A. Rilling, 2008: Aspects of precipitation development in trade wind cumulus revealed by differential reflectivity at S band. J. Atmos. Sci., 65, 2563-2580, https://doi.org/10.1175/2007JAS2569.1.

Kogan, Y. L., D. B. Mechem, and K. Choi, 2012: Effects of sea-salt aerosols on precipitation in simulations of shallow cumulus. J. Atmos. Sci., 69, 463-483, https://doi.org/10.1175/JAS-D-11-031.1.

Lasher-Trapp, S. G., and J. P. Stachnik, 2007: Giant and ultragiant aerosol particle variability over the eastern Great Lakes region. J. Appl. Meteor. Climatol., 46, 651-659, https://doi.org/ 10.1175/JAM2490.1.

_ C. A. Knight, and J. M. Straka, 2001: Early radar echoes from ultragiant aerosol in a cumulus congestus: Modeling and observations. J. Atmos. Sci., 58, 3545-3562, https://doi.org/ 10.1175/1520-0469(2001)058<3545:EREFUA > 2.0.CO;2.

$\longrightarrow$, S. Anderson-Bereznicki, A. Schackelford, C. H. Twohy, and J. G. Hudson, 2008: An investigation of the influence of droplet number concentration and giant aerosol particles upon supercooled large drop formation in wintertime stratiform clouds. J. Appl. Meteor. Climatol., 47, 2659-2678, https:// doi.org/10.1175/2008JAMC1807.1.

Levin, Z., A. Teller, and E. Ganor, 2005: On the interactions of mineral dust, sea-salt particles, and clouds: A measurement and modeling study from the Mediterranean Israeli Dust Experiment campaign. J. Geophys. Res., 110, D20202, https:// doi.org/10.1029/2005JD005810.

Lewis, E. R., and S. E. Schwartz, 2004: Sea Salt Aerosol Production: Mechanisms, Methods, Measurements, and Models-A Critical Review. Geophys. Monogr., Vol. 152, Amer. Geophys. Union, 413 pp.

Lowenstein, J. H., A. M. Blyth, and R. P. Lawson, 2010: Early evolution of the largest-sized droplets in maritime cumulus clouds. Quart. J. Roy. Meteor. Soc., 136, 708-717, https:// doi.org/10.1002/QJ.597.

Matthias-Maser, S., and R. Jaenicke, 1994: Examination of atmospheric bioaerosol particles with radii $>0.2 \mu \mathrm{m}$. J. Aerosol Sci., 25, 1605-1613, https://doi.org/10.1016/0021-8502(94)90228-3.

Mechem, D. B., and Y. L. Kogan, 2008: A bulk parameterization of giant CCN. J. Atmos. Sci., 65, 2458-2466, https://doi.org/ 10.1175/2007JAS2502.1.

Minor, H. A., R. M. Rauber, S. Goke, and L. D. Girolamo, 2011: Trade wind cloud evolution observed by polarization radar: Relationship to giant condensation nuclei concentrations and cloud organization. J. Atmos. Sci., 68, 1075-1096, https:// doi.org/10.1175/2010JAS3675.1.

Mouri, H., K. Okada, and S. Takahashi, 1995: Giant sulfurdominant particles in remote marine boundary-layer. Geophys. Res. Lett., 22, 595-598, https://doi.org/10.1029/ 94GL03394.

Murphy, D. M., and Coauthors, 2019: The distribution of sea-salt aerosol in the global troposphere. Atmos. Chem. Phys., 19, 4093-4104, https://doi.org/10.5194/acp-19-4093-2019. 
NCAR/CISL, 2019: Ngmath library. NCAR, http://ngwww.ucar.edu/ ngmath.

Noone, K. J., R. J. Charlson, D. S. Covert, J. A. Ogren, and J. Heintzenberg, 1988: Design and calibration of a counterflow virtual impactor for sampling of atmospheric fog and cloud droplets. Aerosol Sci. Technol., 8, 235-244, https://doi.org/ 10.1080/02786828808959186.

Okada, K., 1983: Volume fraction of water-soluble material in individual aerosol particles. J. Aerosol Sci., 14, 301-302, https:// doi.org/10.1016/0021-8502(83)90117-9.

Pinnick, R. G., D. M. Garvey, and L. D. Duncan, 1981: Calibration of Knollengerg FSSP light-scattering counters for measurement of cloud droplets. J. Appl. Meteor., 20, 1049-1057, https://doi.org/ 10.1175/1520-0450(1981)020<1049:COKFLS > 2.0.CO;2.

Pitzer, K. S., J. C. Peiper, and R. H. Busey, 1983: Thermodynamic properties of aqueous sodium chloride solutions. Lawrence Berkeley National Laboratory Rep. LBL-15512, 150 pp., https://escholarship.org/uc/item/9jx8f7fd.

Posselt, R., and U. Lohmann, 2008: Influence of giant CCN on warm rain processes in the ECHAM5 GCM. Atmos. Chem. Phys., 8 , 3769-3788, https://doi.org/10.5194/acp-8-3769-2008.

Pruppacher, H. R., and J. D. Klett, 1978: Microphysics of Clouds and Precipitation. D. Riedel, $714 \mathrm{pp}$.

Ranz, W. E., and J. B. Wong, 1952: Impaction of dust and smoke particles on surface and body collectors. J. Ind. Eng. Chem., 44, 1371-1381, https://doi.org/10.1021/ie50510a050.

Reiche, C. H., and S. Lasher-Trapp, 2010: The minor importance of giant aerosol to precipitation development within small trade wind cumuli observed during RICO. Atmos. Res., 95, 386-399, https://doi.org/10.1016/j.atmosres.2009.11.002.

Rosenfeld, D., R. Lahav, A. Khain, and M. Pinsky, 2002: The role of sea spray in cleansing air pollution over ocean via cloud processes. Science, 297, 1667-1670, https://doi.org/10.1126/science.1073869.

_ - D. Axcisa, W. L. Woodley, and R. Lahaw, 2010: A quest for effective hygroscopic cloud seeding. J. Appl. Meteor. Climatol., 49, 1548-1562, https://doi.org/10.1175/2010JAMC2307.1.

Saleeby, S. M., and W. R. Cotton, 2004: A large-droplet mode and prognostic number concentration of cloud droplets in the Colorado State University Regional Atmospheric Modeling System (RAMS). Part I: Module descriptions and supercell test simulations. J. Appl. Meteor., 43, 182-195, https://doi.org/ 10.1175/1520-0450(2004)043<0182:ALMAPN>2.0.CO;2.

Simpson, G. C., 1906: The Beaufort scale of wind-force. Meteorological Office Rep., 54 pp., https://play.google.com/books/reader?id= CcQoAQAAMAAJ\&printsec $=$ frontcover\&output $=$ reader $\&$ $\mathrm{hl}=\mathrm{en} \& \mathrm{pg}=$ GBS.PP1.
Szumowski, M. J., R. M. Rauber, and H. T. Ochs, 1999: The microphysical structure and evolution of Hawaiian rainbands. Part III: A test of the ultragiant nuclei hypothesis. J. Atmos. Sci., 56, 1980-2003, https://doi.org/10.1175/1520-0469(1999) 056<1980:TMSAEO > 2.0.CO;2.

Tang, I. N., A. C. Tridico, and K. H. Fung, 1997: Thermodynamic and optical properties of sea salt aerosols. J. Geophys. Res., 102, 23 269-23 275, https://doi.org/10.1029/97JD01806.

Tzivion, S., and T. Reisin, and Z. Levin, 1994: Numerical simulation of hygroscopic seeding in a convective cloud. J. Appl. Meteor., 33, 252-267, https://doi.org/10.1175/1520-0450(1994) $033<0252: \mathrm{NSOHSI}>2.0 . \mathrm{CO} ; 2$.

Vidaurre, G., and J. Hallett, 2009: Particle impact and breakup in aircraft measurement. J. Atmos. Oceanic Technol., 26, 972983, https://doi.org/10.1175/2008JTECHA1147.1.

Weinzierl, B., and Coauthors, 2017: The Saharan Aerosol Long-Distance Transport and Aerosol-Cloud Interaction Experiment: Overview and selected highlights. Bull. Amer. Meteor. Soc., 98, 1427-1451, https://doi.org/10.1175/BAMS-D15-00142.1.

Willeke, K., and K. T. Whitby, 1975: Atmospheric aerosols: Size distribution interpretation. J. Air Pollut. Control Assoc., 25, 529-534, https://doi.org/10.1080/00022470.1975.10470110.

Wilson, J. C., and Coauthors, 2004: Function and performance of a low turbulence inlet for sampling supermicron particles from aircraft platforms. Aerosol Sci. Technol., 38, 790-802, https:// doi.org/10.1080/027868290500841.

Wood, R., and Coauthors, 2011: The VAMOS Ocean-CloudAtmosphere-Land Study Regional Experiment (VOCALSREx): Goals, platforms, and field operations. Atmos. Chem. Phys., 11, 627-654, https://doi.org/10.5194/acp-11-627-2011.

Woodcock, A. H., 1952: Atmospheric salt particles and raindrops. J. Meteor., 9, 200-212, https://doi.org/10.1175/1520-0469(1952) 009<0200:ASPAR > 2.0.CO;2.

, 1953: Salt nuclei in marine air as a function of altitude and wind force. J. Meteor., 10, 362-371, https://doi.org/10.1175/ 1520-0469(1953)010<0366:SNIMAA $>2.0 . \mathrm{CO} ; 2$.

—, and M. Gifford, 1949: Sampling atmospheric sea-salt nuclei over the ocean. J. Mar. Res., 8, 177-197.

Zhang, L., D. V. Michelangeli, and P. A. Taylor, 2006: Influence of aerosol concentration on precipitation formation in low-level, warm stratiform clouds. J. Aerosol Sci., 37, 203-217, https:// doi.org/10.1016/j.jaerosci.2005.04.002.

Zieger, P., and Coauthors, 2017: Revising the hygroscopicity of inorganic sea salt particles. Nat. Commun., 8, 15883, https:// doi.org/10.1038/NCOMMS15883. 